\title{
O estado da arte da capacidade institucional: uma revisão sistemática da literatura em língua portuguesa
}

\author{
DOUGLAS GOMES MARTINS ${ }^{1}$ \\ ${ }^{1}$ Instituto Federal de Educação, Ciência e TeCnologia do Pará (IFPA), PARAgominas - PA, Brasil
}

\section{Resumo}

Genericamente, a capacidade institucional (Cl) dos governos é compreendida como o conjunto de capacidades das instituições para a consecução dos objetivos públicos. Contudo, as conceituações disponíveis na literatura mostram grande variação. O objetivo deste estudo consistiu na desagregação do constructo capacidade institucional em suas dimensões constitutivas. A busca de variáveis (proxies) atinentes ao contexto brasileiro e que possibilitem, empiricamente, a mensuração e operacionalização da $\mathrm{Cl}$ se deu mediante extensa revisão de literatura a partir de 3 perspectivas: a) a análise da rede de autores teve por objetivo elucidar quais são o(s) pesquisador(es) de referência nos estudos sobre a $\mathrm{Cl}$; b) a técnica de classificação hierárquica descendente (CHD) teve por objetivo distinguir, caso existam, as classes que representam formas distintas de discurso sobre o conceito de $\mathrm{Cl}$; e c) a técnica de árvore de palavras possibilitou a visualização das conexões identificadas entre a palavra-chave, capacidade institucional, e todo o corpus textual. Conclui-se que é possível avançar empiricamente nos estudos sobre a $\mathrm{Cl}$ a partir do exame das dimensões fiscal, administrativa e política dos governos.

Palavras-chave: Capacidade institucional. Revisão sistemática. Classificação hierárquica descendente. Análise de redes. Árvore de palavras.

\section{The state of the art of institutional capacity: a scoping review of the literature in Portuguese}

\begin{abstract}
Government institutional capacity is generally understood as the set of skills observed in governmental institutions, which are necessary to achieve public goals. However, there are numerous conceptualizations in the literature. This study aimed to breakdown institutional capacity, into its constitutive dimensions. The search for proxies active in the Brazilian context and that empirically allow measuring the operationalization of institutional capacity took place after an extensive literature review from three perspectives: a) analysis of the network of authors, identifying the main researchers exploring the topic of institutional capacity, b) a descending hierarchical classification technique aimed to distinguish the classes (if any) that represent distinct forms of discourse on the concept of institutional capacity, and c) the word tree technique, which identified connections between the keyword institutional capacity, and the entire textual corpus. We conclude that it is possible to advance empirically in studies on institutional capacity by examining the government's fiscal, administrative, and political dimensions.
\end{abstract}

Keywords: Institutional capacity. Scooping review. Descending hierarchical classification. Network analysis. Word tree.

\section{El estado del arte de la capacidad institucional: una revisión sistemática de la literatura en portugués}

\section{Resumen}

En general, la capacidad institucional de los gobiernos se entiende como el conjunto de capacidades que las instituciones tienen para lograr los objetivos públicos. Sin embargo, las conceptualizaciones presentes en la literatura muestran una gran variación. El objetivo de este estudio consistió en el desglose del constructo "capacidad institucional", en sus dimensiones constitutivas. La búsqueda de variables proxy relacionadas con el contexto brasileño y que permitan empíricamente la medición y operacionalización de la capacidad institucional se llevó a cabo mediante una extensa revisión de la literatura desde tres perspectivas: 1) el análisis de la red de autores, cuyo objetivo fue dilucidar cuáles son los investigadores de referencia en los estudios sobre capacidad institucional; 2) la técnica de clasificación jerárquica descendente cuyo propósito fue distinguir, si existieran, las clases que representan formas distintas de discurso sobre el concepto de capacidad institucional; y 3) la técnica de árbol de palabras, que permitió ver las conexiones identificadas entre la palabra clave, la capacidad institucional y todo el corpus textual. Se concluye que es posible avanzar empíricamente en los estudios sobre capacidad institucional examinando las dimensiones fiscal, administrativa y política de los gobiernos.

Palabras clave: Capacidad institucional. Revisión sistemática. Clasificación jerárquica descendente. Análisis de redes. Árbol de palabras. 


\section{INTRODUÇÃO}

Quando o interesse em estudar o Estado, como ator ou instituição, foi destacado a partir de amplo número de publicações acadêmicas, nos mais diversos campos do conhecimento, o tema capacidade institucional (Cl) ganhou relevância. Na América Latina, os incipientes estudos sobre a $\mathrm{Cl}$ estiveram intimamente relacionados à segunda geração de reformas do Estado na década de 1990 e foram pautados pelos princípios que norteiam o modelo de administração gerencial, inspiração dessas reformas (Huerta, 2008; Skocpol, 1985).

Assim, as evidências acadêmicas sugerem que o conceito de $\mathrm{Cl}$ surgiu na década de 1980, com base na análise dos organismos internacionais de financiamento (a exemplo do Banco Mundial) que tinham o objetivo de mensurar a eficiência de alguns países ao aplicar os investimentos concedidos por essas instituições internacionais de fomento. Logo, o conceito de $\mathrm{Cl}$ se associou, em um primeiro momento, às concepções de técnicas de reengenharia organizacional com enfoque nas estruturas internas das organizações (Huerta, 2008; Lessik \& Michener, 2000; Mizrahi, 2004).

Segundo Mizrahi (2004), mesmo que o conceito tenha ganhado a atenção de governos e da academia, ainda há pouca concordância sobre como definir, operacionalizar, mensurar e aprimorar a $\mathrm{Cl}$, devido à abrangência desse conceito. Além desse cenário, ressalta-se a multiplicidade de conceituações e metodologias de mensuração que incidem sobre os estudos que envolvem a Cl (Cingolani, 2013).

Essa constatação é corroborada pela análise dos trabalhos nacionais que abordam o tema Cl (Lubambo \& Coutinho, 2004; Silva, 2015; Veloso, Monasterio, Vieira \& Miranda, 2011). A depender do estudo, a Cl é associada: a) ao grau de governabilidade dos governos (promoção dos canais participativos, transparência das ações governamentais, etc.); b) à capacidade de gestão (priorizando os eixos de: finanças, capital e infraestrutura, pessoas, e tecnologia da informação); e c) à atuação do Estado (na definição e implementação de estratégias de desenvolvimento e transformação da realidade).

Destarte, o desenvolvimento deste estudo visou a responder às seguintes inquietações:

- Qual é o atual estado da arte dos estudos sobre a capacidade institucional na academia brasileira?

- É possível avançar empiricamente nos estudos sobre a capacidade institucional de modo a compreender quais são os principais elementos constitutivos que podem influenciá-la?

Assim, o objetivo deste estudo consistiu no aprofundamento do conceito de $\mathrm{Cl}$, de modo a identificar como ele foi abordado pela produção científica de artigos no Brasil, no âmbito da administração pública, em um período de 10 anos (de 2008 a 2018).

A revisão sistemática contou com o auxílio de softwares de análise lexicográfica e análise de redes - IRAMUTEQ, MAXQDA e Pajek - dessa forma, a análise lexicográfica possibilitou a subdivisão do constructo $\mathrm{Cl}$ em suas partes constitutivas, de modo a evidenciar as variáveis (proxies) atinentes ao contexto brasileiro que possibilitem, empiricamente, sua mensuração e operacionalização. A análise das redes de autores evidenciou o estado da arte e a existência de eventuais pesquisadores de referências nos estudos sobre a $\mathrm{Cl}$, além de viabilizar a verificação de conexões entre os referenciais bibliográficos dos artigos selecionados para a revisão integrativa; já a técnica da árvore de palavras interativa proporcionou a visualização das conexões identificadas entre a palavra-chave, capacidade institucional, e todo o corpus textual selecionado para a revisão de literatura.

Este artigo está organizado da seguinte maneira: a) após esta introdução, temos uma breve discussão teórico-conceitual do escopo da revisão sistemática de literatura; b) a terceira seção descreve as metodologias propostas e a operacionalização da revisão integrativa sobre $\mathrm{a} \mathrm{Cl}$; c) os resultados são discutidos na quarta seção; e d) o texto se encerra com a apresentação de nossas conclusões e das implicações práticas desta pesquisa.

\section{REFERENCIAL TEÓRICO}

\section{Uma breve revisão sobre capacidade institucional}

Etimologicamente, o substantivo capacidade deriva do latim capacitas e relaciona-se à habilidade ou aptidão de uma pessoa, ou algo, para realizar uma tarefa, também se associando ao conceito de eficiência. Já o termo institucional, também de origem latina, provém de institutĭo, que significa criação, formação (Glosbe, 2018). Na academia, a concatenação desses dois termos está intimamente ligada à administração pública, tendo seu significado ligado à capacidade de um Estado para elaborar e operacionalizar políticas públicas. 
Há estudos de referência sobre o conceito de $\mathrm{Cl}$, dentre os principais se destaca Evans (1995). O autor analisa a capacidade dos Estados a partir de determinadas características, como a qualidade da burocracia pública, o nível de autonomia de tal burocracia no relacionamento com as estruturas que a permeiam e a tipologia do comportamento dos Estados. Por sua vez, Painter e Pierre (2005) examinam a Cl sob a perspectiva das habilidades dos governos para fazer escolhas inteligentes e definir estratégias, com vistas à alocação eficiente de recursos. Já Huerta (2008) relaciona a Cl à busca pela eficiência, a partir de um conjunto de medidas que proporcione às gestões públicas uma $\mathrm{Cl}$ adequada para melhorar suas funções, adaptar suas instituições, formular e implementar políticas e ser responsável (accountable), no âmbito de um sistema de gestão pública.

Com fundamento nesses referenciais teóricos, observa-se que o ponto de concordância sobre a definição de $\mathrm{Cl}$ consiste no estabelecimento de uma relação causal entre as instituições e os resultados almejados por elas, ou seja, ter uma $\mathrm{Cl}$ adequada condiciona o bom desempenho dos governos. No âmbito desta pesquisa, a $\mathrm{Cl}$ se relaciona às ações governamentais e compreende o conjunto de capacidades necessárias para a consecução de seus objetivos institucionais (Cruz et al., 2011).

Há na literatura um esforço para se mensurar a $\mathrm{Cl}$ em termos quantitativos, ainda que parte dos estudos tenha predominância qualitativa. Com vistas a verificar se há concordância em relação às variáveis usadas, foram analisados artigos que mensuraram empiricamente o constructo $\mathrm{Cl}$. O resultado desta pesquisa, que envolveu a última década, é apresentado no Quadro 1.

\section{Quadro 1}

\section{Autores que operacionalizam empiricamente a mensuração da capacidade institucional de 2009-2019}

\begin{tabular}{|c|c|c|}
\hline Autores & Variáveis usadas & Título do artigo e ano de publicação \\
\hline $\begin{array}{l}\text { 1. Kris Hartley } \\
\text { e J. Zhang }\end{array}$ & $\begin{array}{l}\text { Níveis de comunicação; consulta e coordenação intra e interinstitucional; níveis } \\
\text { de finanças e pessoal; transparência; presença do Estado de direito; acesso } \\
\text { à informação; sistema fiscal adequado para financiar programas e projetos. }\end{array}$ & $\begin{array}{l}\text { Measuring policy capacity through } \\
\text { governance indices, } 2016 .\end{array}$ \\
\hline $\begin{array}{l}\text { 2. Gomide e } \\
\text { Boschi }\end{array}$ & $\begin{array}{l}\text { Burocracias eficientes; reaparelhamento da matriz produtiva; fomento ao } \\
\text { desenvolvimento; adoção de políticas de inclusão social com efeitos distri- } \\
\text { butivos; ampliação da democracia. }\end{array}$ & $\begin{array}{l}\text { Capacidades estatais para políticas públi- } \\
\text { cas em países emergentes: (des)vantagens } \\
\text { comparativas do Brasil, } 2016 \text {. }\end{array}$ \\
\hline $\begin{array}{l}\text { 3. Luciana } \\
\text { Cingolani }\end{array}$ & $\begin{array}{l}\text { Combinação das seguintes dimensões do poder do Estado: a) coer- } \\
\text { citiva (direitos de propriedade); b) fiscal; c) administrativa; } \\
\text { d) transformadora ou industrializante; e) cobertura relacional/territorial; } \\
\text { f) legal; g) política. }\end{array}$ & $\begin{array}{l}\text { The state of State capacity: a review of } \\
\text { concepts, evidence and measures, } 2013 .\end{array}$ \\
\hline $\begin{array}{l}\text { 4. Lindvall e } \\
\text { Teorell }\end{array}$ & $\begin{array}{l}\text { Capacidade fiscal; burocracia especializada; informação; coerção; incenti- } \\
\text { vos e propaganda. }\end{array}$ & $\begin{array}{l}\text { State capacity as power: a conceptual } \\
\text { framework, } 2016 .\end{array}$ \\
\hline $\begin{array}{l}\text { 5. Pires e } \\
\text { Gomide }\end{array}$ & $\begin{array}{l}\text { Especialização da burocracia; diálogo entre governo e sociedade; desempe- } \\
\text { nho; análise dos resultados. }\end{array}$ & $\begin{array}{l}\text { Governança e capacidades estatais: uma aná- } \\
\text { lise comparativa de programas federais, } 2015 .\end{array}$ \\
\hline $\begin{array}{l}\text { 6. Sandra } \\
\text { Gomes }\end{array}$ & $\begin{array}{l}\text { Fiscal (receita tributária própria e recursos de transferências intergoverna- } \\
\text { mentais); administrativa (qualificação do pessoal, estrutura organizacional, } \\
\text { resultados de implementação); política (accountability, transparência, canais } \\
\text { de comunicação, presença de organismos reguladores). }\end{array}$ & $\begin{array}{l}\text { The multi-faceted debate on decentraliza- } \\
\text { tion and collective welfare, } 2010 .\end{array}$ \\
\hline $\begin{array}{l}\text { 7. Angélica } \\
\text { Huerta }\end{array}$ & $\begin{array}{l}\text { Capacidade administrativa (Estado de direito, especialização da burocracia, } \\
\text { estrutura e distribuição de funções e responsabilidades, disponibilidade de } \\
\text { recursos financeiros, relacionamento, coordenação e colaboração intergo- } \\
\text { vernamental); capacidade política (canais de comunicação e participação } \\
\text { política, transparência e accountability). }\end{array}$ & $\begin{array}{l}\text { Una ruta metodológica para evaluar la } \\
\text { capacidad institucional, } 2008 .\end{array}$ \\
\hline $\begin{array}{l}\text { 8. André Luís } \\
\text { Nogueira }\end{array}$ & $\begin{array}{l}\text { Uso de indicadores administrativos, fiscais e políticos. Respectivamente: estru- } \\
\text { tura organizacional dos governos estaduais, despesas liquidadas na função } \\
\text { assistência social e presença de conselhos de políticas públicas. }\end{array}$ & $\begin{array}{l}\text { Os estados no SUAS: uma análise da capa- } \\
\text { cidade institucional ( } \mathrm{Cl} \text { ) dos governos esta- } \\
\text { duais, } 2015 .\end{array}$ \\
\hline $\begin{array}{l}\text { 9. Helen J. } \\
\text { Addison }\end{array}$ & $\begin{array}{l}\text { Capacidade de coordenação (arranjos burocráticos e suas ligações colabo- } \\
\text { rativas com organizações dominantes da sociedade civil), capacidade de } \\
\text { implementação (prestação de serviços) e capacidade de responsabilização. }\end{array}$ & $\begin{array}{l}\text { Is administrative capacity a useful concept? } \\
\text { Review of the application, meaning and } \\
\text { observation of administrative capacity in } \\
\text { political science literature, } 2009 .\end{array}$ \\
\hline $\begin{array}{l}\text { 10. Hanson e } \\
\text { Sigman }\end{array}$ & $\begin{array}{l}\text { Identificaram três fatores da capacidade: administrativo, fiscal (função extra- } \\
\text { tiva) e potencial coercitivo. }\end{array}$ & $\begin{array}{l}\text { Leviathan's latent dimensions: measuring } \\
\text { State capacity for comparative political } \\
\text { research, } 2013 .\end{array}$ \\
\hline
\end{tabular}

Fonte: Elaborado pelo autor. 
Como mostra o Quadro 1, a literatura tem grande variedade na elaboração, decomposição e operacionalização dos conceitos sobre a Cl. Enquanto alguns pesquisadores enfocam o diagnóstico da Cl dos estados brasileiros na assistência social (Silva, 2015), outros apresentam uma percepção mais abrangente da $\mathrm{Cl}$, levando em conta os graus de competência e os níveis de recursos usados para a produção de políticas públicas, que se subdividem em doze dimensões para a análise da Cl (Howlett, 2015).

Por isso, de acordo com Cingolani (2013), existem diferentes abordagens para a mensuração da Cl, sendo a estratégia mais comum para o estudo da $\mathrm{Cl}$ as abordagens que envolvem criação de indicadores (uni ou multidimensionais).

Corroborando Cingolani (2013), para Gomes (2010) existem muitas abordagens empíricas relativas à Cl. No caso brasileiro, o foco recai, geralmente, sobre a relação das três esferas de governo. Isso se deve ao fato do ambiente federativo ser propício para a discussão da $\mathrm{Cl}$, uma vez que seus entes concorrem nas capacidades do Estado. Ponderemos três dessas principais abordagens.

A primeira abordagem enfoca a descentralização fiscal como uma dimensão suficiente e necessária para explicar o aumento da $\mathrm{Cl}$ dos governos. Especificamente, sustenta-se a concepção de que a liberdade de tributar e alocar recursos por parte dos governos subnacionais é a chave para o aumento de sua $\mathrm{Cl}$. Com base nos conceitos de equilíbrio de mercado, os teóricos dessa vertente sugerem que os governos locais conhecem melhor as preferências e as necessidades de seus cidadãos em relação ao governo central. A expectativa, segundo Oates (1999), é que esse nível de governo conseguiria obter informações com menor custo, além de poder, de modo mais eficiente, propor e implementar políticas públicas atinentes às necessidades percebidas.

Dessa forma, ocorreria uma "competição saudável por clientes", incitando os governos locais a fornecer as melhores cestas de produtos/serviços públicos com as menores taxas de impostos.

Por sua vez, é possível desenvolver um análogo a concorrência perfeita no setor privado. Nesse cenário, os governos competem entre si por um estoque de capital que gera renda para os residentes locais e fornece uma base tributária para eles - e essa competição leva as autoridades locais a adotar níveis eficientes de produção de bens públicos e alíquotas de impostos. Nesses modelos, a "mão invisível" funciona da mesma maneira que no setor privado, para canalizar decisões políticas em jurisdições individuais em um resultado eficiente de uma perspectiva nacional (Oates, 1999, p. 1135, tradução nossa).

Contudo é importante ressaltar que, nesse modelo interpretativo, desconsideram-se os elementos políticos, estruturais e institucionais, como: a) a motivação dos políticos; b) o papel das burocracias locais; c) a atuação dos stakeholders nos processos decisórios; d) a estrutura organizacional; e) o capital humano etc. Isso limita o papel dos governos centrais na criação de políticas que necessitam de coordenação nacional, tais como as transferências intergovernamentais e as políticas macroeconômicas.

A segunda abordagem concebe os governos subnacionais não como entidades autônomas, mas como entidades inseridas em um contexto de regulação governamental, logo, essa linha de análise representa um avanço no sentido de considerar os aspectos administrativos, fiscais e políticos da descentralização, além de seus respectivos impactos na Cl dos governos. Essa vertente explicativa propõe uma ruptura com a noção simplificada de que existe uma única condição que é suficiente para a autonomia e para o aumento da capacidade dos governos subnacionais.

A principal crítica desse grupo de análises está relacionada à operacionalização das medidas que devem refletir conceitos analíticos, por um lado, e às dificuldades inerentes aos estudos comparativos, por outro, principalmente quando a distinção entre graus e formas de descentralização torna a análise mais complexa. A variação nas maneiras de se classificar graus e tipos de descentralização também acaba produzindo resultados discrepantes (Gomes, 2010, p. 115, tradução nossa).

Entretanto, a principal crítica aos teóricos dessa vertente advém da inexistência de uniformidade sobre a operacionalização e a mensuração das informações referente aos níveis de descentralização e a $\mathrm{Cl}$. Mostra-se necessária a criação de um referencial conceitual comum para posteriores pesquisas empíricas. A terceira concepção se refere à eficácia do processo de descentralização no desenho institucional das reformas. Desse modo, a adoção de projetos institucionais específicos aumentaria a $\mathrm{Cl}$ das estruturas administrativas, por exemplo, a partir do aumento: a) da accountability; b) dos mecanismos de responsabilidade fiscal; c) da institucionalização de canais de participação social; d) da garantia de capacidades fiscais e administrativas para a provisão de serviços etc. 
Todavia, Litvack, Ahmad e Bird (1998, p. 2, tradução nossa) salientam que a capacitação fiscal e administrativa dos governos locais deveria preceder a adoção desses projetos institucionais e, por esse motivo, os governos de diversos países em desenvolvimento muitas vezes não respondem aos seus cidadãos, porque "as tomadas de decisão raramente são transparentes e previsíveis. As oportunidades de cobrança e os resultados são limitados por causa de instituições fracas". Nessa acepção, as instituições são consideradas fracas quando não têm $\mathrm{Cl}$ para a prestação de serviços ao coletivo social. Os elementos apresentados possibilitam a associação entre o processo de reformas de descentralização e a $\mathrm{Cl}$ dos entes subnacionais. Depreende-se que as regras institucionais podem gerar efeitos que variam conforme o contexto em que são adotadas, pelo fato de considerar-se que as ações do governo central limitam a autonomia de escolha do "pacote de políticas" e, em decorrência, interferem no desempenho dos governos subnacionais.

Vale ressaltar a existência de questionamentos que sucedem as três interpretações explicativas, destacando-se: a) o mimetismo teórico, oriundo de contextos diversos do brasileiro; b) a variabilidade da prestação de serviços, como um mecanismo de desigualdades; e c) as especificidades inerentes a cada território, uma vez que as localidades teriam diferentes capacidades (fiscais, administrativas, etc.) para responder às "preferências" de seus cidadãos.

\section{A relevância da revisão sistemática sobre a capacidade institucional}

O crescente emprego dos métodos de investigação denominados "revisão sistemática" ou "revisão integrativa" de literatura traz à tona a necessidade de ordenar toda a literatura produzida por um, ou mais, campos de conhecimento sobre uma temática específica. Nesse sentido, embora não exista uma definição universalmente aceita sobre a revisão sistemática de literatura, é consensual que a característica mais marcante desse método é a possibilidade de uma visão geral sobre um tópico, reconhecidamente amplo (Peterson, Pearce, Ferguson \& Langford, 2017).

Logo, o processo de mapeamento e estruturação de informações propiciadas pela revisão sistemática de literatura visa a demonstrar o atual estado da arte e elucidar a existência de lacunas, ou oportunidades, de conhecimento sobre determinado tema, contribuindo para posteriores investigações científicas.

Complementarmente, Ramos, Faria e Faria (2014) salientam que, devido ao crescente número de indivíduos que se beneficiam de um amplo conjunto de recursos disponíveis no ambiente virtual, torna-se cada vez mais complexa a atividade de seleção e de valoração do que é, ou não, cientificamente relevante. Por esse motivo, a revisão sistemática de literatura serve como um facilitador, como um importante instrumento agregador de conhecimentos, de modo a auxiliar o alcance do propósito deste estudo, ou seja, a compreensão da estrutura teórico-conceitual do tema $\mathrm{Cl}$ na academia nacional.

Esta revisão de literatura se baseou nos indícios fornecidos pelos estudos sobre a $\mathrm{Cl}$ existentes na literatura internacional, os quais sublinharam, por um lado, a necessidade de criação de uma estrutura conceitual que permita a compreensão do conceito de $\mathrm{Cl}$ e, por outro, expuseram a natureza subjetiva das variáveis representativas da $\mathrm{Cl}$, característica que dificulta a criação de uma definição consensual que abranja toda a teoria que envolve essa temática (Addison, 2009; DeRouen et. al., 2010; Lessik \& Michener, 2000; Wu, Ramesh \& Howlett, 2015).

Portanto, mostra-se importante o mapeamento teórico da $\mathrm{Cl}$ no contexto nacional, tendo em vista proporcionar ao campo científico da administração pública importantes subsídios teóricos. Esse mapeamento é descrito por meio da operacionalização da revisão sistemática de literatura na próxima seção.

\section{METODOLOGIA}

Esta pesquisa constitui um trabalho descritivo de abordagem mista, isto é, qualitativa e quantitativa, porque se propõe a descrever um fenômeno $(\mathrm{Cl})$ a partir do exame dos estudos realizados sobre a $\mathrm{Cl}$ na academia. Para tanto, empregaram-se testes estatísticos para quantificar todo o material verbal coletado e dele extrair suas unidades de sentido (Camargo \& Justo, 2013).

Segundo Rumrill, Fitzgerald e Merchant (2010) e Silva, Fonseca, Mafra e Freitas (2016) o processo de revisão sistemática, ou integrativa, constitui uma forma preliminar de investigação que busca identificar, avaliar e interpretar toda a pesquisa relevante sobre determinado tema, de modo a proporcionar a síntese do conhecimento produzido e fornecer subsídios para 
o campo científico, auxiliando a formulação de questões e propostas para pesquisas posteriores. Para atingir tais propósitos, esta revisão integrativa foi operacionalizada com o auxílio dos softwares IRAMUTEQ, Pajek e MAXQDA.

O IRAMUTEQ é um software livre que viabiliza análises estatísticas de material verbal transcrito. Ele auxilia a análise lexicográfica de determinado corpus de palavras e traduz a essência dos textos selecionados por meio de classificação hierárquica descendente (CHD), possibilitando a descrição, classificação e interpretação das palavras com base nas diretrizes da análise de conteúdo (Camargo \& Justo, 2013; Ratinaud \& Marchand, 2012).

O Pajek também é um software livre e sua finalidade consiste na análise e visualização de redes. Suas principais contribuições se referem à possibilidade de análise de grandes redes sociais e do emprego de algoritmos que facilitam a representação gráfica de matrizes de dados para auxiliar a interpretação das redes sociais de modo integrado (Molina, Muños \& Doménech, 2002).

A ferramenta, árvore de palavras, disponível no software MAXQDA, possibilita ao pesquisador analisar como determinadas palavras, ou locuções, são usadas em frases ou discursos em um corpus textual. Assim, a árvore de palavras fornece a visualização das conexões identificadas entre a palavra-chave, capacidade institucional, e todo o corpus textual selecionado, por meio de um sistema de ramificações (Wattenberg \& Viégas, 2008).

Para elucidar o atual estado da arte e avançar empiricamente nos estudos sobre a Cl, mostrou-se necessária a compreensão dos artigos que compõem o tema $\mathrm{Cl}$. Portanto, justifica-se o uso de ferramentas que auxiliam o processo de revisão integrativa, de modo a possibilitar a exploração dos dados e das informações em um âmbito mais amplo (Levy \& Ellis, 2006). Além desses fatores, ressalta-se que os softwares não impõem uma abordagem metodológica, pelo contrário, trata-se de uma ferramenta complementar, por isso, cabe ao pesquisador a seleção e aplicação das diferentes estratégias que nortearão seu(s) estudo(s) (Saillard, 2011).

\section{Operacionalização}

Os procedimentos adotados nesta revisão sistemática de literatura seguiram as orientações sugeridas por Ramos et al. (2014) (Quadro 2).

\section{Quadro 2}

Operacionalização da revisão integrativa

\begin{tabular}{|c|c|}
\hline & $\begin{array}{l}\text { Investigar a produção científica, o estado da arte da academia brasileira, sobre o tema capacidade } \\
\text { institucional (Cl), sintetizar informações, contribuir com a formulação de questões e propostas para } \\
\text { pesquisas posteriores e avançar empiricamente nos estudos sobre a Cl. }\end{array}$ \\
\hline & “Capacidade institucional”. \\
\hline & Todas as bases de dados contidas no Portal de Periódicos CAPES no âmbito da administração pública. \\
\hline & $\begin{array}{l}\text { Só serão selecionados os artigos publicados que se encaixem na temática de verificação proposta } \\
\text { (CI), com um Qualis Capes igual ou superior a B2 e dentro do marco temporal definido para a revisão, } \\
\text { ou seja, artigos publicados entre janeiro de } 2008 \text { e março de } 2018 \text {. }\end{array}$ \\
\hline & $\begin{array}{l}\text { Artigos que não se encontram no Qualis Capes estipulado, artigos anteriores ao marco temporal } \\
\text { definido, artigos fora do âmbito da administração pública e artigos que não tenham resumo e não } \\
\text { estejam redigidos em língua portuguesa. }\end{array}$ \\
\hline & Classificação hierárquica descendente (CHD), análise de redes e análise textual. \\
\hline & $\begin{array}{l}\text { Registro dos passos, analisar e descrever criticamente os resultados com ajuda dos softwares } \\
\text { IRAMUTEQ, Pajek e MAXQDA. }\end{array}$ \\
\hline
\end{tabular}

Fonte: Elaborado pelo autor. 
O modelo proposto por Ramos et al. (2014) reforça a necessidade de realizar a revisão integrativa em sete etapas. Nessa perspectiva, contemplam-se o planejamento, a execução e a análise dos resultados.

\section{Registro dos passos}

A etapa de coleta dos artigos sobre $\mathrm{Cl}$ foi realizada entre janeiro de 2018 e março de 2018 . Nesse intervalo foram examinados 102 artigos com potencial de análise. Destes, 31 foram selecionados e tiveram seus dados extraídos e analisados, de acordo com as recomendações previstas no protocolo de operacionalização (Apêndice).

O critério de seleção de artigos para a revisão sistemática de literatura foi processado em três etapas. Na primeira etapa, a palavra-chave, capacidade institucional, foi incluída no campo de pesquisas avançadas do Portal de Periódicos CAPES. Após a primeira etapa, foram selecionados todos os artigos, transcritos em português, que apresentassem resumo, conforme o protocolo de inclusão. Na etapa seguinte, após a leitura dos resumos e das introduções dos artigos selecionados, foram incluídos aqueles cuja temática fosse condizente com o âmbito da administração pública. Na última etapa, após a leitura minuciosa de todos os artigos selecionados, foi elaborado o corpus textual para posterior análise nos softwares aplicados neste estudo.

A opção pela fonte de busca (indexador) Portal de Periódicos CAPES se deveu a diversos fatores, dentre os quais se destacam: a) a facilidade de acesso à informação científica via internet; b) a possibilidade de acesso a conhecimento atualizado; e c) a inclusão dos principais periódicos (bases) no âmbito da administração pública em seu acervo on-line.

A opção pelos estratos que compreendem o Qualis Capes B2 a A1 se deu pelo fato de eles serem considerados os mais relevantes em termos de qualidade da produção intelectual dos programas de pós-graduação no Brasil (Coordenação de Aperfeiçoamento de Pessoal de Nível Superior [CAPES], 2018). Ademais, Pedroso e Pilatti (2009) ressaltam que os trabalhos compreendidos nos estratos B2, B1, A2 e A1, de acordo com a Classificação de Periódicos CAPES para a Administração no Quadriênio 2013-2016, podem ser considerados proxy de relevância e abrangência.

O critério de inclusão de artigos redigidos somente na língua portuguesa se relacionou, em um primeiro momento, à proposta de avaliação da produção científica nacional sobre o tema da $\mathrm{Cl}$ e, em um segundo momento, à impossibilidade dos softwares analisarem um mesmo corpus textual com línguas diferentes.

\section{Operacionalização da classificação hierárquica descendente}

Para a exploração e análise dos dados, todo o material incluído foi analisado no software IRAMUTEQ, versão 0.7, alpha 2. Para tanto, os segmentos textuais selecionados foram ligados a um único arquivo, denominado "Corpus Textual". Cada artigo foi identificado por uma linha de comando que demarcou as características que constituiriam o escopo da "análise estatística textual". Vale ressaltar que o corpus textual processado no software IRAMUTEQ foi composto pelos resumos e pelas introduções de todos os artigos que atenderam às especificações da revisão de literatura. Também é importante ressaltar a necessidade de alterações no corpus textual para a otimização da análise do software, a partir da análise lexical clássica.

Com base nos estudos de Azevedo e Miranda (2012) e Silva et al. (2016), empregaram-se os seguintes métodos de análise:

A) Análise lexical clássica: essas interfaces realizam o processo de lematização das palavras, ou seja, elas classificam as formas reduzidas de algumas palavras, como, por exemplo, criação, criativo, criacionismo, que serão classificadas como "criar". No entanto, cada palavra é classificada de acordo com seu tipo gramatical. Após essa etapa, realizou-se a análise das frequências e o teste qui-quadrado $\left(\mathrm{chi}^{2}\right)$ de cada palavra do corpus textual com sua respectiva forma reduzida. Dessa forma, é possível verificar a probabilidade de existência de associação entre as formas/palavras e as variáveis trabalhadas ou o corpus textual.

B) Método de classificação hierárquica de Reinert (CHD): esse método possibilita a contabilização das palavras pela frequência de co-ocorrência, tendo como base as classes gramaticais carregadas de significados cognitivos passíveis de exame. Portanto, realizam-se cálculos a partir da co-ocorrência de palavras em segmentos de texto, de modo a distinguir as classes de palavras que representam formas distintas de discurso sobre o tópico de interesse da investigação. Dessa forma, tendo por base a "classificação hierárquica descendente", as classes são representadas comparativamente com seu grau de ocorrência e similitude.

Foram considerados, tanto na análise lexical clássica quanto no método de Reinert (CHD), apenas os segmentos textuais cujos escores qui-quadrado fossem iguais a $3,84(p \leq 0,05)$, ou seja, os valores significativos. 


\section{Operacionalização da análise de redes}

Os trabalhos desenvolvidos internacionalmente sobre redes sociais podem ser observados em quatro fases distintas. A fase que demarca o contexto atual se caracteriza pela maior facilidade de acesso à informação (internet) e evolução das ferramentas computacionais, a exemplo dos programas e softwares de análise de redes (Zampier, 2007). Segundo Lopes (1997), existem importantes revisões de literatura sobre a teoria e a análise de redes, sendo que o estudo de Stanley Wasserman e Katherine Faust (1994) apresenta uma abrangente revisão das metodologias de análise de redes sociais e suas aplicações.

Com o intuito de verificar quais são os pesquisadores que são referência nos estudos sobre a Cl e de elucidar a existência de conexões entre os referenciais teóricos de todos os artigos, conduziu-se a análise de rede dos artigos selecionados para a revisão integrativa e dos seus respectivos referenciais bibliográficos. Assim, a análise das citações expressou uma relação entre 2 pares: a) o autor do texto citado; e b) o autor do texto citante. Conforme os textos científicos vão se citando, eles criam um emaranhado de relações que auxiliam a compreensão do estado da arte de determinado tema, consolidando a análise da rede de autores (Romancini, 2010).

Para a elaboração da rede foram caracterizados como (nós) os artigos selecionados para a revisão integrativa e para estabelecer a interconexão entre eles foram consideradas as citações desses artigos. Portanto, os pontos (nós) na cor cinza correspondem aos 31 artigos selecionados para a revisão integrativa. Os pontos (nós) na cor vermelha são os artigos referenciados, cada citação será caracterizada com uma seta (arcs) (Figura 3). A centralidade da rede é definida pela quantidade de relações existentes entre um ator (nó) e outros atores. Isso quer dizer que os atores mais centrais são os que têm maior quantidade de relações com os demais autores que estudaram o conceito de $\mathrm{Cl}$ e, por isso, desenvolvem um papel mais importante dentro da rede (Wasserman \& Faust, 1994).

As denominações mais comuns na análise de redes foram sintetizadas com a intenção de facilitar a compreensão do estudo (Quadro 3). A partir da criação das redes são analisadas as características dos grupos, a densidade e a centralidade dos autores. É importante salientar que algoritmo de Fruchterman-Reingold (2-D) do software Pajek, versão 64 5.05, facilitou esse processo, de modo a possibilitar a visualização das redes de autores e sua interpretação.

\section{Quadro 3}

\section{Estruturas de dados do software Pajek}

\begin{tabular}{|c|l|}
\hline Nós & $\begin{array}{l}\text { São as pessoas ou grupos de pessoas que se agrupam com um objetivo comum. } \\
\text { Os nós se representam por círculos. A soma de todos os nós indica o tamanho da rede. }\end{array}$ \\
\hline Arcos/fluxos & $\begin{array}{l}\text { São as linhas que representam a ligação entre dois vértices, porém, elas apresentam } \\
\text { sinalização de direção. }\end{array}$ \\
\hline Densidade & $\begin{array}{l}\text { A densidade da rede demonstra a conectividade dos atores que compreendem a rede. } \\
\text { Ou seja, ela elucida o número de relações existentes diante do número de relações } \\
\text { possíveis. }\end{array}$ \\
\hline Centralidade & $\begin{array}{l}\text { O grau de centralidade consiste no número de nós com os quais um nó está diretamente } \\
\text { relacionado. }\end{array}$ \\
\hline $\begin{array}{c}\text { Outdegree/ } \\
\text { grau de saída }\end{array}$ & O grau de saída é a soma das interações que os atores (nós) têm com os outros. \\
\hline
\end{tabular}

Fonte: Elaborado pelo autor.

\section{Operacionalização da árvore de palavras}

De acordo com Gibbs (2009) e Evers (2011), os softwares de análise de dados qualitativos se caracterizam como programas que otimizam a análise qualitativa dos textos. Logo, o uso dos softwares altera a maneira como os pesquisadores tratam dados qualitativos, uma vez que facilitam a visualização das relações entre conjuntos de dados e possibilitam a codificação, categorização e associação das classes presentes nos textos analisados. Além disso, permite a replicação de todos os processos, tornando-os, não somente mais ágeis, como também mais transparentes.

A operacionalização da ferramenta árvore de palavras, disponível no software MAXQDA, versão 12.3.2, iniciou-se com a inserção da palavra-chave, capacidade institucional, na caixa de pesquisa. Após esse processo, a palavra-chave foi mapeada em todos os artigos selecionados para a revisão integrativa, que também foram inseridos no banco de dados do software. 
Assim as várias palavras e contextos semânticos subsequentes à palavra-chave definiram as ramificações da árvore de palavras. Portanto, o uso dessa ferramenta possibilita tanto a visualização do contexto em que a terminologia, capacidade institucional se encaixa, quanto o exame de eventuais divergências conceituais que forem observadas nos 31 artigos selecionados para a revisão integrativa (Henderson \& Segal, 2013).

Dessa forma, o uso da árvore de palavras serve para complementar a análise dos resultados a partir da identificação de padrões de significação e da organização espacial da terminologia estudada nos artigos selecionados para a revisão integrativa.

\section{RESULTADOS E DISCUSSÕES}

\section{Descrição dos dados}

A etapa de descrição dos dados observou os seguintes critérios: a) ano de publicação; b) relevância das publicações (Qualis Capes); e c) delineamento do estudo (abordagem metodológica).

Pelo exame do ano das publicações, verificou-se tanto a incipiência dos estudos acadêmicos quanto o gradual aumento no número de publicações sobre o tema $\mathrm{Cl}$, uma vez que grande parte das publicações dos artigos se concentrou no intervalo compreendido entre os anos de 2014 a 2016 (Figura 1). A relativa ausência de publicações nos anos 2017 e 2018 pode relacionar-se ao período de avaliação dos artigos.

Figura 1

Número de publicações sobre a capacidade institucional de 2008 a 2018

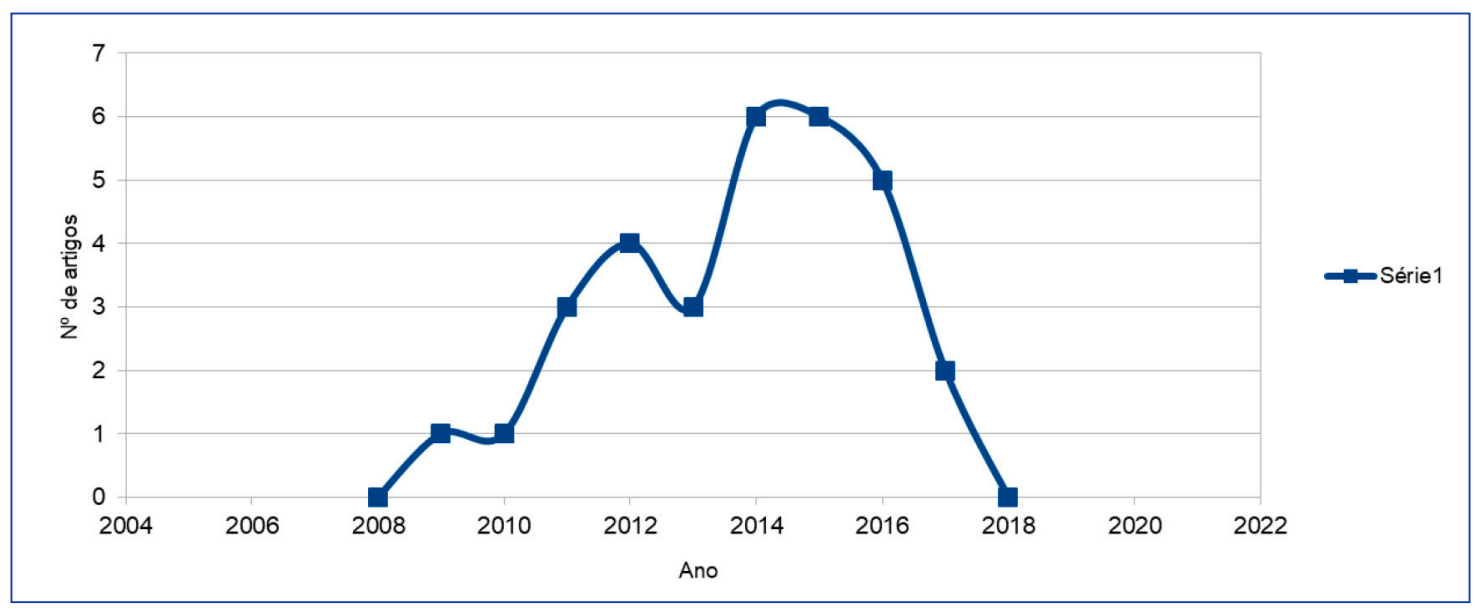

Fonte: Elaborada pelo autor.

Pela análise da relevância e abrangência das publicações, verificou-se que a ausência de artigos sobre a Cl em periódicos que se encontram no estrato A1 da plataforma "Qualis Capes" pode refletir a opção metodológica desta pesquisa, ao incorporar na revisão integrativa somente artigos redigidos na língua portuguesa. No entanto, a predominância de publicações no estrato A2 (55\% dos artigos) indica que o tema $\mathrm{Cl}$, no contexto nacional, tem relevância no campo acadêmico.

Outra informação relevante foi obtida a partir da análise do delineamento das pesquisas sobre a Cl. Notou-se a multiplicidade de abordagens metodológicas como: ensaios teóricos e estudos que exploraram simultaneamente as abordagens qualitativa e quantitativa nas pesquisas sobre o tema $\mathrm{Cl}$ (Tabela 1 ). 
Tabela 1

Análise de abordagens nos estudos sobre a capacidade institucional

\begin{tabular}{|c|c|c|c|c|c|}
\hline Abordagem metodológica & Frequência & \multicolumn{4}{|c|}{ Estrato Qualis Capes (Percentual) } \\
\hline Ensaio teórico & 1 & \multicolumn{4}{|c|}{ B2 (100\%) } \\
\hline Quantitativa & 15 & \multicolumn{4}{|c|}{ A2 (56,3\%); B1 (40\%); B2 (20\%) } \\
\hline Qualitativa & 9 & \multicolumn{4}{|c|}{ A2 (25\%); B1 (30\%); B2 (60\%) } \\
\hline Mista & 6 & \multicolumn{4}{|c|}{ A2 (18,8\%); B1 (30\%) } \\
\hline Total & 31 & $\begin{array}{l}\text { Ensaio } \\
3,2 \%\end{array}$ & $\begin{array}{c}\text { Qualitativa } \\
32,3 \%\end{array}$ & $\begin{array}{c}\text { Quantitativa } \\
45,2 \%\end{array}$ & $\begin{array}{l}\text { Mista } \\
19,4 \%\end{array}$ \\
\hline
\end{tabular}

Fonte: Elaborada pelo autor.

Complementarmente, realizou-se o teste qui quadrado $\left(\mathrm{chi}^{2}\right)$, com o intuito de analisar o grau de associação entre o "Qualis Capes" dos periódicos e o delineamento metodológico adotado. Logo, não é possível rejeitar a hipótese (H0), de que existe associação entre o "Qualis Capes" dos periódicos e o delineamento das pesquisas.

Dado esse contexto, pode-se considerar que a temática da $\mathrm{Cl}$ na literatura nacional é recente, abrangente, tem grande potencial de publicação em diversos âmbitos de pesquisa e abarca diferentes abordagens metodológicas. Contudo, os estudos com enfoque na $\mathrm{Cl}$ ainda carecem de consenso, situação verificada a partir da pluralidade teórica dos referenciais analisados que se discute posteriormente.

\section{Classificação hierárquica descendente}

A primeira fase da análise lexical evidenciou as informações relativas à visualização dos dados mais gerais do corpus textual. Este foi constituído por 31 unidades de contextos iniciais (UCI). Utilizando o teste qui-quadrado, as $31 \mathrm{UCI}$ foram decompostas em 4.498 unidades de contexto elementares (UCE), o que totalizou 25.221 ocorrências textuais analisadas. Nesse número de ocorrências havia 3.188 palavras distintas. A partir da padronização do vocabulário, sua forma raiz, analisaram-se 2.066 ocorrências de palavras.

De acordo com Nascimento e Menandro (2006) e com Azevedo e Miranda (2012), o agrupamento das raízes semânticas e a definição de classes leva em consideração a função da palavra em determinado texto. Logo, tanto é possível quantificar quanto inferir acerca da delimitação das classes, uma vez que o método de CHD contabiliza as palavras a partir de: ocorrência, co-ocorrência e função textual das palavras no corpus textual, de modo a distinguir as classes que representam formas distintas de discurso sobre o tópico de interesse da investigação.

Dessa forma, tendo por base a "classificação hierárquica descendente", as classes são representadas comparativamente com seu grau de ocorrência e similitude, de modo a possibilitar: a descrição, classificação e interpretação dos segmentos de texto. O dendrograma (Figura 2) estruturou a subdivisão das classes que compõem o corpus textual desta pesquisa. 
Figura 2

Classificação hierárquica descendente

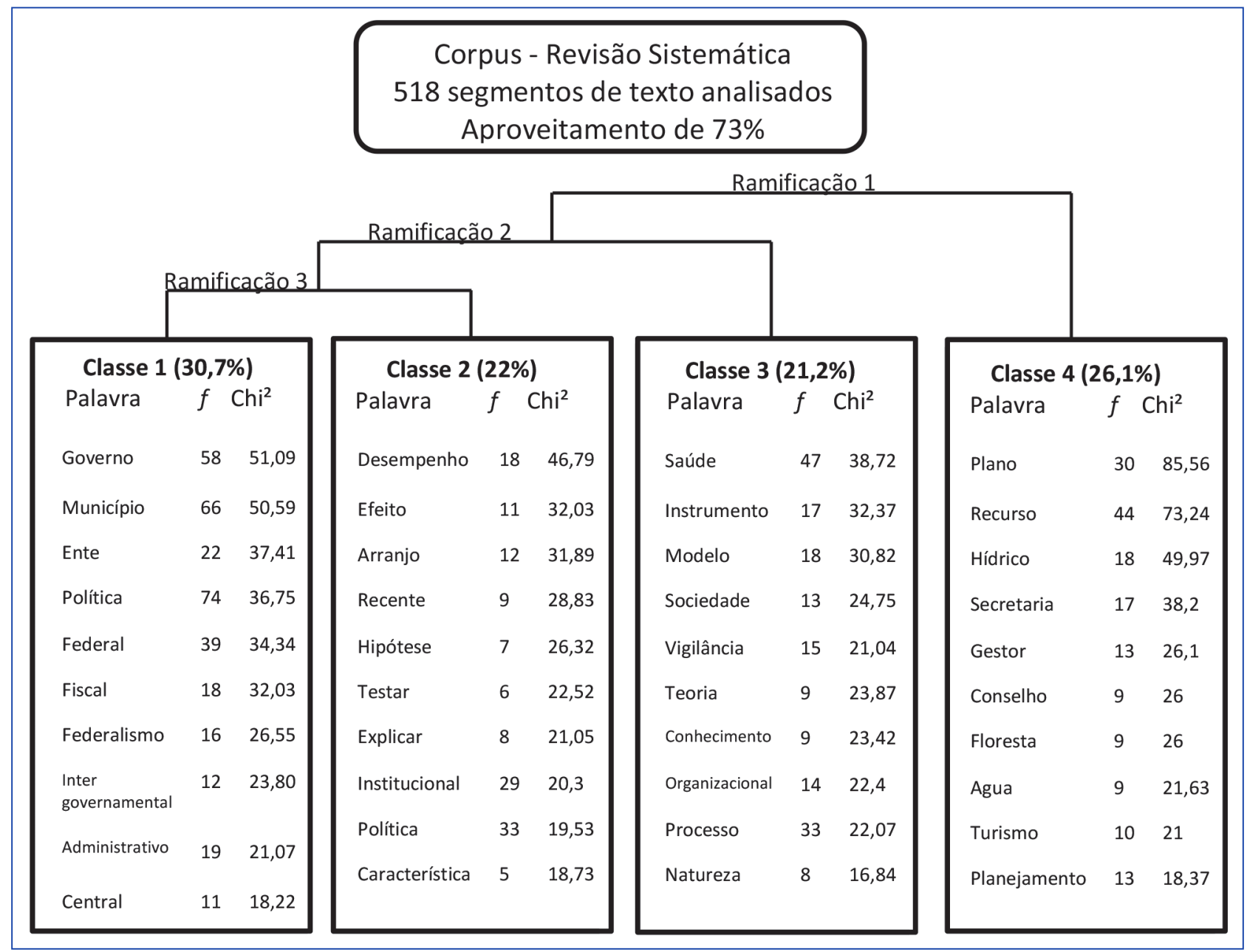

Fonte: Elaborada pelo autor.

Como ilustrado na Figura 2, o corpus textual o corpus textual foi dividido em 4 classes, subdivididas em 3 ramificações. Para a melhor visualização das características de cada classe foram elencadas as 10 palavras mais expressivas, segundo: a) sua frequência $(f)$; e b) seu grau de associação $\left(\mathrm{chi}^{2}\right)$ com a classe correspondente.

No entanto, antes de iniciar as discussões sobre os resultados provenientes do método de CHD, é importante elucidar que o percentual de retenção e aproveitamento dos textos analisados foi superior ao especificado pela literatura vigente (Camargo \& Justo, 2013; Ratinaud \& Merchand, 2012). Desse modo, foram aproveitados 73\% dos segmentos de texto, o equivalente a 518 segmentos de texto presentes nos 31 artigos selecionados para a revisão integrativa de literatura.

A Classe 1, considerada a de maior poder explicativo, envolveu 158 UCE, de modo a representar 30,7\% de todo o corpus textual. A Classe 4 foi formada por 135 UCE, o que correspondeu a 26,1\% do corpus textual. Por sua vez, as classes 2 e 3 representaram, respectivamente, $21,2 \%$ e $22 \%$ do corpus. Dessa forma, observou-se que a terceira ramificação, composta pelas classes 1 e 3, explica melhor o conteúdo analisado, isso quer dizer que a terceira ramificação, que apresenta um poder de explicação equivalente a $51,9 \%$ de todo o corpus textual, é considerada a mais relevante na compreensão dos artigos referentes ao tema $\mathrm{Cl}$.

Com fundamento em todas as informações disponibilizadas, depreende-se que a classe 4, denominada "Referencial Teórico", traduz-se na estrutura basilar de todo o corpus textual presente nos artigos analisados. Ou seja, na classe 4 se encontram as teorias mais gerais, relacionadas às demais classes $(2,1$ e 3$)$. Ao analisar a rede de palavras formada na classe 4 , verifica-se 
o conteúdo lexical agrupado, principalmente, ao redor das palavras: plano e recurso. Situação explicada pelos seguintes trechos, extraídos das $\mathrm{UCl}$ da classe 4:

[...] o plano de fortalecimento da gestão do turismo, do patrimônio natural e cultural dos municípios [...] também tem como missão garantir que os municípios possuam autonomia de identificar e buscar os outros canais de financiamento disponíveis pelo governo federal [...] (Araújo \& Possenato, 2012, p. 223) (UCl 28).

[...] Outra relevante observação pontuada pelos autores, diz respeito à dificuldade em se alcançar resultados positivos por meio da política ambiental, pois a reflexão ambiental é incipiente em muitos países e, por tal razão, a industrialização e a própria constituição da vida em sociedade são destoantes do modelo de preservação ambiental, fatos esses que se tornam obstáculos para a efetiva redução dos níveis de poluição. Dentre os mais recorrentes problemas tangenciais à sua implementação e fiscalização, faz-se pertinente citar: a falta de recursos monetários, a baixa capacidade institucional e ainda, a insuficiência de recursos humanos [...] (Neitzk, Gonçalves, Oliveira, Machado \& Gibbon, 2015, p. 75) (UCI 14).

Conclui-se que os segmentos de texto representativos da classe 4 constituíram elementos relacionados à pesquisa de cada artigo, seja no âmbito: a) do planejamento administrativo; b) do planejamento societal; c) da gestão federal; ou d) dos níveis subnacionais de governo (estados e municípios). Também é importante salientar que o tema $\mathrm{Cl}$ aparece, genericamente, nos planos de governo e de fortalecimento da $\mathrm{Cl}$. Em suma, da classe 4 derivam as demais ramificações que formarão as demais classes.

A classe 2, denominada "Discussões", pertencente a segunda ramificação, tem uma relação mais forte com a classe 4, o que implica sua dependência, no sentido de explicar as questões propostas pela primeira ramificação. Dessa forma, apesar do menor percentual de retenção de segmentos textuais, o agrupamento de palavras saúde, sociedade, vigilância sanitária e natureza (gestão ambiental) evidencia o lócus de cada pesquisa, ao passo que os segmentos de texto instrumento, modelo, teoria e conhecimento se relacionam à fundamentação teórica e à operacionalização metodológica empregada por cada artigo. Os trechos extraídos das UCl expõem essas informações:

[...] Essas teorias ocuparam-se de conceitos teóricos como cultura corporativa, produtividade organizacional, comunicações e modelos e práticas gerenciais, entre outros. O conceito de capacidade institucional tem mostrado suas limitações ao focalizar o objeto de estudo nas organizações em aspectos puramente técnicos [...] (Vidal, 2014, p. 668) (UCI 4).

[...] O instrumento de monitoramento foi construído após o delineamento do modelo lógico da gestão da vigilância em saúde e os indicadores representativos de cada componente da gestão passaram por processo de validação. Além de subsidiar a tomada de decisão, o monitoramento é entendido enquanto prática reflexiva capaz de promover o aprendizado pessoal e institucional, melhoria contínua dos processos de gestão, maior transparência e responsabilização [...] (Costa, Felisberto, Bezerra, Cesse \& Samico, 2013, p. 1201) (UCI 24).

A terceira ramificação é considerada a de maior poder de explicação porque, somadas, as classes 1 e 3 correspondem a aproximadamente $52 \%$ de todo o corpus textual analisado.

Conforme a Figura 3, a terceira ramificação se subdivide em 2 subcorpus, as classes 1 e 3, que, apesar de terem divergências em sua estruturação, apresentam um conteúdo comum, o objeto de análise, isto é, a Cl. Tal subdivisão expõe, por um lado, a classe 1 - que se relaciona à fundamentação teórica oriunda das dimensões de análise da $\mathrm{Cl}$ - e, por outro, a classe 3 - que evidencia a relação causal entre as hipóteses de pesquisa e o exame da $\mathrm{Cl}$.

A classe 3, denominada "Resultados", indica as hipóteses de pesquisa e as especificidades inerentes aos resultados e efeitos atribuídos ao aumento ou à diminuição da $\mathrm{Cl}$. É importante salientar que, nessa classe, o conceito de $\mathrm{Cl}$ permanece amplo, relacionando-se ao escopo de cada pesquisa, ou seja, não há uma definição precisa do que é ou quais são as condições indispensáveis para a existência ou o aumento da $\mathrm{Cl}$. Os segmentos textuais mais representativos da classe 3 são: desempenho e efeito. Os trechos selecionados das UCl embasam a interpretação proposta: 
[...] os resultados, por sua vez, sugerem que as capacidades institucionais exercem um efeito positivo sobre o desenvolvimento econômico. Em outras palavras, quanto maior a capacidade institucional de um país, maior será seu desempenho econômico [...] (Silva, Cunha, Domingos \& Torres, 2015, p. 332) (UCI 20).

[...] se propõe analisar os determinantes da atuação as prefeituras brasileiras, sob a ótica da eficiência governamental. O objetivo principal é analisar os efeitos da competição eleitoral sobre a eficiência dos governos locais na implementação das políticas sociais [...] (Cavalcante, 2013, p. 1570) (UCI 3).

O exame da classe 1, denominada "Dimensões da Capacidade Institucional", elucidou uma situação excepcional, onde as palavras governo, município, ente, federal, federalismo e central sinalizaram os diferentes níveis de governo influenciadores e influenciados pela $\mathrm{Cl}$ :

[...] Os sistemas políticos federativos são caracterizados pela existência de distribuição territorial da autoridade política, o que implica dizer que, em um mesmo território dentro de um mesmo Estado, mais de um governo pode ser responsável pelo exercício do poder político. Os entes federados possuem assim autonomia - que pode variar entre os diversos modelos de sistemas federativos existentes [...] (Pallotti \& Costa, 2011, p. 211) (UCI 30).

Já o agrupamento de palavras política, fiscal e administrativa sinalizou as dimensões de análise da $\mathrm{Cl}$.

[...] No caso dos programas de governo implementados com o propósito de fortalecer a capacidade institucional de entes federativos e setores da administração pública, parece haver estreito vínculo entre capacidade institucional e capacidade de planejamento e de gestão das políticas públicas pela racionalização dos processos administrativos, modernização dos sistemas de informação, estabelecimento de relações com atores de cooperação e colaboração [...] (Fernandes, 2016, p. 703) (UCI 10).

[...] utilizam-se indicadores fiscais, administrativos e políticos para mensurar a capacidade institucional dos 26 governos estaduais e do DF na assistência social. Isso servirá para verificarmos se a criação de sistemas nacionais de políticas públicas contribui no fortalecimento institucional das esferas de governo, no caso deste trabalho, nos governos estaduais [...] (Silva, 2015, p. 1169) (UCI 11).

Dessa forma, notou-se que a expectativa teórica presente na classe 1 , relacionada às dimensões da $\mathrm{Cl}$, vai de encontro à expectativa teórica de renomados pesquisadores sobre a Cl, como Huerta (2008), Gomes (2010), Cingolani (2013) e Wu et al. (2015), os quais ressaltam que um dos maiores desafios para os estudos sobre a Cl é a "mensuração de desempenho" e que grande parte desses estudos são pautados por uma confusão entre meios e fins na tentativa de mensurar a Cl. Nesse sentido, é possível depreender que, para avançar empiricamente, um estudo sobre a $\mathrm{Cl}$ não pode prescindir das dimensões destacadas pela classe 1, isto é, as dimensões administrativa, política e fiscal.

\section{Análise de redes}

O principal objetivo do emprego da técnica de análise de redes foi compreender o estado da arte dos estudos sobre a $\mathrm{Cl}$ no Brasil, por meio de redes de citações dos artigos selecionados para a revisão integrativa. De acordo com Soares (1989, p. 3), a compreensão do estado da arte de um campo do conhecimento se mostra necessária para o processo de evolução desse campo, de modo a permitir "a indicação de possibilidades de integração de diferentes perspectivas (aparentemente autônomas), a identificação de duplicações ou contradições, e a determinação de lacunas e vieses". De forma complementar, a análise de redes também visou examinar a existência de algum(a) pesquisador(a) de referência em estudos sobre a Cl.

Desse modo, a análise de redes de citações é determinante para indicar as fontes de informação que mais influenciam a literatura nacional sobre o tema $\mathrm{Cl}$. Logo, a rede foi criada a partir dos nós cinzas (que representam os 31 artigos selecionados para a revisão integrativa), dos nós vermelhos (que representam as bibliografias dos 31 artigos) e dos arcos (que representam as citações entre os nós).

De posse desses parâmetros, observou-se que a rede de autores sobre a $\mathrm{Cl}$ tem densidade bastante baixa (0,14\%), indicando que a rede é esparsa e possui pouca coesão, situação oposta à ideal, ou seja, com a presença de redes de autores densas e amplamente integradas. Isso implica a existência de artigos que, apesar de abordarem a temática da $\mathrm{Cl}$, não apresentam sequer 
um referencial bibliográfico comum, são "ilhas teóricas", além do fato dos artigos selecionados para a revisão integrativa não dialogarem diretamente entre si (Figura 3). Também não se identificou um(a) autor(a) brasileiro(a) com elevado número de publicações dentre os 31 artigos selecionados para a revisão integrativa; destacaram-se os autores Fabiana Silva Fernandes e Eduardo José Grin, com 2 publicações cada.

Portanto, a não consolidação do estado da arte do tema $\mathrm{Cl}$ é verificada pela falta de diálogo e a baixa densidade das relações entre os artigos selecionados para a revisão integrativa, pela centralidade da Constituição Federal (CF) de 1988 como referencial teórico mais citado nos 31 artigos selecionados e pela existência de "ilhas teóricas", isto é, de artigos que apresentam sua própria estrutura de estudo sobre a $\mathrm{Cl}$ (Figura 3).

Figura 3

Análise da rede dos autores

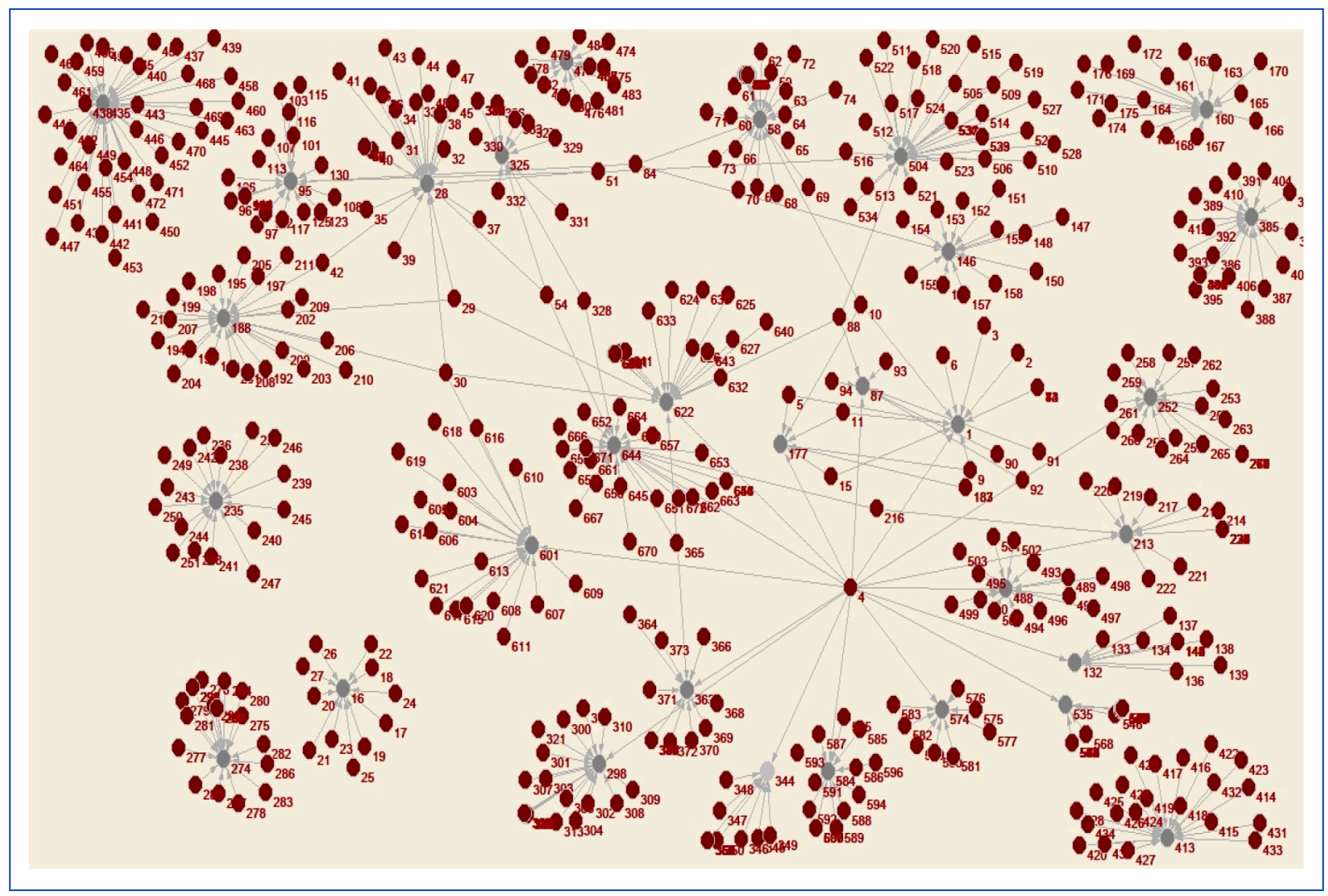

Fonte: Elaborada pelo autor.

A centralidade da rede de autores é definida pela quantidade de relações existentes entre um ator (nó) e outros atores. Isso quer dizer que os atores mais centrais são aqueles que têm maior quantidade de relações com outros atores e, por isso, assumem um papel mais importante dentro de determinada rede (Wasserman \& Faust, 1994).

Nessa análise se sobressai a Constituição Federal de 1988, com um grau de centralidade “outdegree/grau de saída" igual a 17, ou seja, a Constituição de 1988 se caracteriza como a principal referência para os autores que estudaram a $\mathrm{Cl}$, sendo citada em 17 dos 31 artigos selecionados para a revisão integrativa.

Com o intuito de facilitar a compreensão da estrutura das redes de autores sobre a $\mathrm{Cl}$, a Tabela 2 destaca os rótulos das bibliografias citadas (nós vermelhos) com maior centralidade na rede de autores. Dessa forma, pode-se visualizar a presença de pelo menos três grupos de análise.

O primeiro grupo se caracteriza por leis, decretos e normas oriundos da Constituição Federal de 1988, que são específicas a cada contexto de pesquisa sobre a Cl. Essa característica ressalta a baixa densidade da rede e a não consolidação do estado da arte sobre a $\mathrm{Cl}$, uma vez que tais leis, decretos e normas restringem o conceito de $\mathrm{Cl}$, subdividindo-o em funções 
específicas em detrimento de uma abordagem mais geral. O segundo grupo se relaciona aos autores que pesquisam o contexto do federalismo brasileiro, a exemplo de Marta Arretche e Celina Souza, ratificando a necessidade dos estudos sobre a Cl contextualizarem o arcabouço institucional dos governos estudados (Lindvall \& Teorel, 2016). O terceiro grupo, por sua vez, faz menção aos artigos referentes, especificamente, ao conceito de Cl, a saber: Cruz et al. (2011), Lubambo e Coutinho (2004), Lessik e Michener (2000), e Mizhari (2004), os quais estabelecem diretrizes e fundamentações teóricas para a mensuração e análise desse conceito.

Tabela 2

Rótulos da rede

\begin{tabular}{|c|c|c|c|}
\hline $\begin{array}{l}\text { Código da } \\
\text { bibliografia }\end{array}$ & Bibliografia & Ano & $\begin{array}{l}\text { Número de citações } \\
\text { (centralidade } \\
\text { outdegree) }\end{array}$ \\
\hline 4 & $\begin{array}{l}\text { Constituição da República Federativa do Brasil de 1988. (1988). Brasília, DF: } \\
\text { Presidência da República. }\end{array}$ & 1988 & 17 \\
\hline 30 & $\begin{array}{l}\text { Arretche, M., \& Marques, E. (2002). Municipalização da saúde no Brasil: diferenças } \\
\text { regionais, poder do voto e estratégias de governo. Ciência \& Saúde Coletiva, } 7(3) \text {, } \\
\text { 455-479. }\end{array}$ & 2002 & 4 \\
\hline 5 & $\begin{array}{l}\text { Cruz, M. C. M. T., Montoro, F. A. F., Bio, S. R., Viana, M. T., Craveiro, S. S., \& Castro, } \\
\text { T. P. (2011). Gestão pública no Estado de São Paulo: elementos para um olhar } \\
\text { analítico. In J. F. A. Veloso, L. M. Monasterio, R. S. Vieira, \& R. B. Miranda (Orgs.), } \\
\text { Gestão municipal no Brasil: um retrato das prefeituras (pp. 87-140). Brasília, DF: } \\
\text { Instituto de Pesquisa Econômica Aplicada. }\end{array}$ & 2011 & 3 \\
\hline 9 & $\begin{array}{l}\text { Lessik, A., \& Michener, V. (2000). Measuring institutional capacity (Recent Practices in } \\
\text { Monitoring and Evaluation Tips, n. 15). Washington, DC: International Development } \\
\text { Cooperation Agency/United States Agency for International Development. }\end{array}$ & 2000 & 3 \\
\hline 29 & $\begin{array}{l}\text { Arretche, M. (2004). Federalismo e políticas sociais no Brasil: problemas de } \\
\text { coordenação e autonomia. São Paulo em Perspectiva, 18(2), 17-26. }\end{array}$ & 2004 & 3 \\
\hline 10 & $\begin{array}{l}\text { Lubambo, C. W. (2002). Conselhos gestores e desempenho da gestão nos municípios: } \\
\text { potencialidades e limites (Textos para Discussão, n. 149). Recife, PE: Fundação } \\
\text { Joaquim Nabuco. }\end{array}$ & 2002 & 3 \\
\hline 54 & $\begin{array}{l}\text { Souza, C. (2005). Federalismo, desenho contitucional e instituições federativas no } \\
\text { Brasil pós-1988. Revista de Sociologia e Política, 24, 105-121. }\end{array}$ & 2005 & 3 \\
\hline 88 & $\begin{array}{l}\text { Arretche, M. (1999). Estado federativo e políticas sociais: determinantes da } \\
\text { descentralização. Revista Brasileira de Ciências Sociais, 14(40), 111-141. }\end{array}$ & 1999 & 3 \\
\hline 633 & $\begin{array}{l}\text { Evans, P. B., Rueschmeyer, D., \& Skocpol, T. (2002). On the road toward a more } \\
\text { understanding of the state. In P. B. Evans, D. Rueschmeyer, \& T. Skocpol (Eds.), } \\
\text { Bringing the State Back In (pp. 347-366). Cambridge, UK: Cambridge University Press. }\end{array}$ & 2002 & 2 \\
\hline 11 & $\begin{array}{l}\text { Mizrahi, Y. (2004). Capacity enhancement indicator: review of the literature. } \\
\text { Washington, DC: World Bank Institute. }\end{array}$ & 2004 & 2 \\
\hline
\end{tabular}

Fonte: Elaborado pelo autor.

Logo, este estudo salientou a falta de diálogo entre os autores nacionais que abordam o tema Cl. Também se evidenciou a existência de lacunas, indicando incoerências conceituais, em decorrência da não consolidação do estado da arte do tema $\mathrm{Cl}$ no âmbito nacional. Daí a necessidade de revisões com o intuito de mapear o estado da arte e debater as diferentes perspectivas que circundam o tema em questão. 


\section{Árvore de palavras interativa}

Com o intuito de aprofundar a análise de conteúdo e complementar a análise dos resultados deste estudo, procedeu-se à técnica árvore de palavras interativa, operacionalizada pelo software MAXQDA.

Dessa forma, a árvore de palavras é composta pelos elementos denominados raiz, que são ligados a outros elementos denominados folhas, de modo a identificar os princípios semânticos que determinam as correlações observadas nessa revisão de literatura (MAXQDA, 2018). Logo, o emprego dessa técnica forneceu tanto a visualização das combinações que levam o conceito de $\mathrm{Cl}$ dentro dos artigos selecionados para a revisão integrativa quanto à importância dos contextos semânticos, uma vez que o tamanho da palavra é proporcional à sua frequência nos textos (Figura 4).

A partir da estrutura da árvore de palavras se observou que a palavra-chave, capacidade institucional, apresenta uma multiplicidade de atores, significações, e instrumentalizações que envolvem sua construção conceitual. Constatou-se que os estudos sobre a $\mathrm{Cl}$ abrangem os três níveis de governo brasileiros (federal, estadual e municipal), expostos pela CHD, e também políticas, programas e avaliações de distintas ações governamentais (assistência social, gerenciamento e ordenamento do solo, políticas educacionais, etc.), corroborando as considerações apresentadas por Huerta (2008) e Wu et al. (2015) acerca da necessidade dos estudos sobre a $\mathrm{Cl}$ combinarem todos os componentes (subtipos e dimensões) dessa capacidade, no sentido de obter uma explicação menos subjetiva e/ou relacionada a determinados contextos de pesquisa.

Portanto, esta pesquisa revelou a falta de um quadro teórico global e consolidado que subsidie a compreensão teórico-aplicada do conceito de $\mathrm{Cl}$ e de suas especificidades. No entanto, também foi ressaltado o grande potencial de pesquisa a ser explorado por essa temática, principalmente no âmbito governamental, devido à multiplicidade de níveis de governo, atores e instrumentos de mensuração que abrangem o tema, capacidade institucional.

Dessa forma, essa pesquisa evidenciou que o conceito de $\mathrm{Cl}$ se associa às ações governamentais, considerando seus distintos níveis, e pode ser entendido como o conjunto de competências institucionais necessárias para a consecução dos objetivos públicos.

\section{CONCLUSÃO}

Tendo em vista os resultados da revisão integrativa, verificou-se o grande potencial de publicação dos estudos sobre a temática da $\mathrm{Cl}$ na literatura nacional, a abrangência do conceito e sua adaptabilidade a diferentes abordagens metodológicas.

De posse de todas as informações obtidas por meio da análise de conteúdo dos 31 artigos selecionados para a revisão integrativa, pode-se aferir que: a) o Estado assume papel de destaque nos estudos sobre $\mathrm{Cl}$, situação inteligível pela centralidade de leis, decretos e normas oriundos da Constituição Federal de 1988, constatada na análise de redes e mediante a técnica da árvore de palavras interativa; b) os autores nacionais que trataram o tema da $\mathrm{Cl}$ atribuíram maior grau de importância às dimensões: administrativa, política e fiscal c) os autores, ao estudarem e operacionalizarem o conceito de $\mathrm{Cl}$, o fazem em diferentes contextos de pesquisa com vistas à explicação de um conjunto particular/específico de resultados (performance em educação, saúde, turismo etc.). Em relação à última observação, Lindvall e Teorell (2016) e Addison (2009) salientam que compreender a $\mathrm{Cl}$ a partir de enfoques específicos limita a apliçção desse conceito.

Destarte, os resultados desta pesquisa convergiram com a literatura internacional sobre $\mathrm{Cl}$ ao expor a existência de uma multiplicidade de perspectivas sobre o tema $\mathrm{Cl}$ e a importância de realizar pesquisas empíricas e ensaios teóricos nesse âmbito.

Também se mostra importante evidenciar que os argumentos apresentados nesta pesquisa não foram corroborados empiricamente, daí a necessidade de estimar a $\mathrm{Cl}$ de modo a permitir o exame desse construto nas diferentes nas diferentes perspectivas que o circunscrevem. Outra limitação se relacionou à impossibilidade de analisar simultaneamente textos redigidos em português e inglês, limitando os resultados desta pesquisa.

Apesar dessas limitações, este estudo defende a tese de que a $\mathrm{Cl}$ pode ser definida pelas ações governamentais e compreende o conjunto de capacidades necessárias para a consecução de seus objetivos institucionais. Sendo que sua manifestação empírica pode ser analisada sob uma ótica tripartite, de modo a abarcar os níveis fiscal, administrativo e político. Ressalta-se que tais dimensões foram consideradas relevantes a partir da análise do conteúdo das publicações nacionais sobre o tema Cl.

Para futuras pesquisas, sugere-se a análise do grau de $\mathrm{Cl}$ dos estados brasileiros, a partir das dimensões explicitadas por esta pesquisa. 


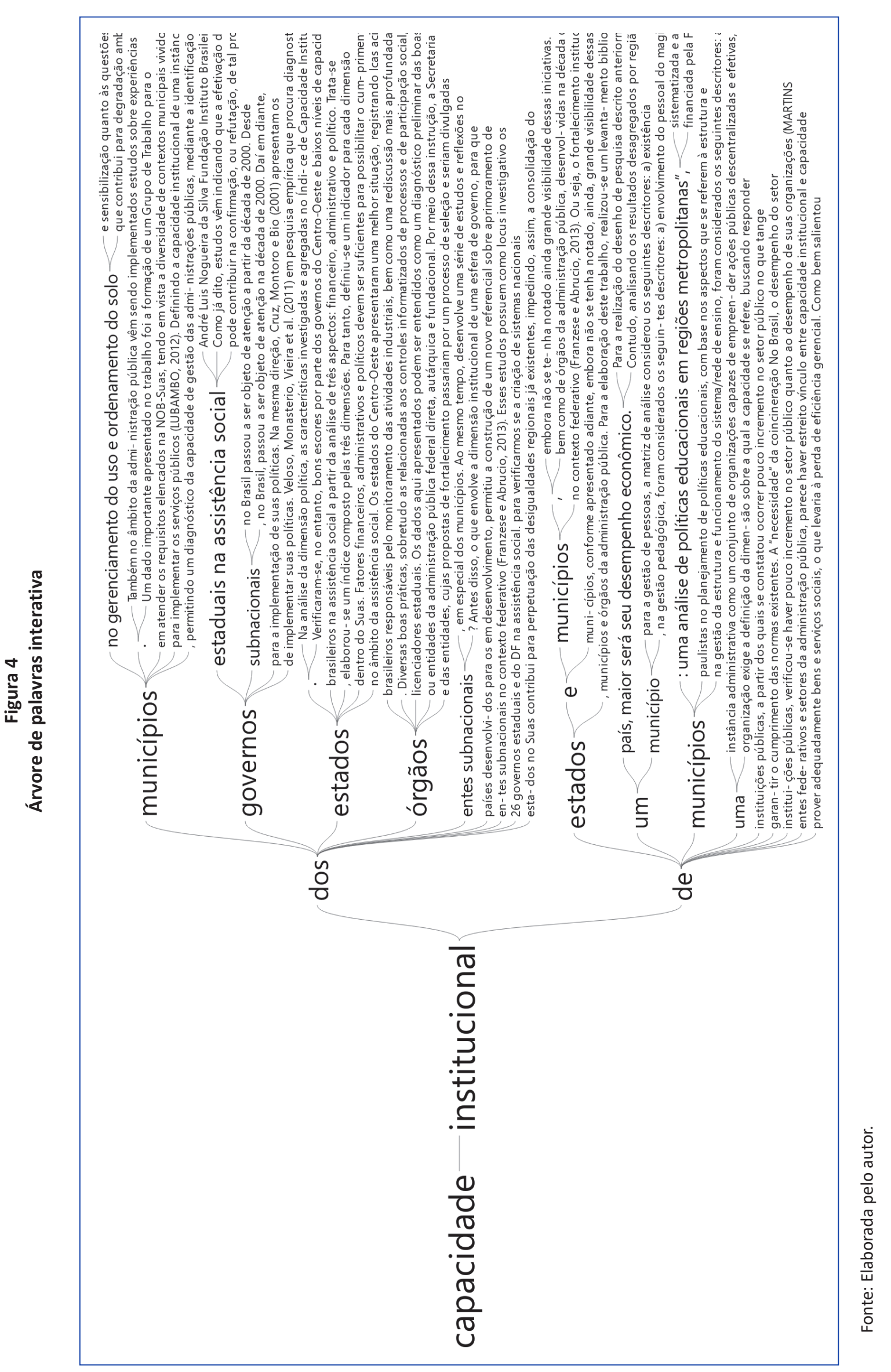




\section{REFERÊNCIAS}

Addison, H. J. (2009). Is administrative capacity a useful concept? Review of the application, meaning and observation of administrative capacity in political science literature applications of the concept of capacity. London, UK: London School of Economics.

Araújo, R. M., \& Posenatto, A. F. G. (2012). Plano de Fortalecimento da Gestão do Turismo (PFGT): uma avaliação ex ante no município de Nísia Floresta (RN). Revista de Administração Pública, 46(1), 221-248.

Arretche, M. (1999). Estado federativo e políticas sociais: determinantes da descentralização. Revista Brasileira de Ciências Sociais, 14(40), 111-141.

Arretche, M. (2004). Federalismo e políticas sociais no Brasil: problemas de coordenação e autonomia. São Paulo em Perspectiva, 18(2), 17-26.

Arretche, M., \& Marques, E. (2002). Municipalização da saúde no Brasil: diferenças regionais, poder do voto e estratégias de governo. Ciência \& Saúde Coletiva, 7(3), 455-479.

Azevedo, D. M., \& Miranda, F. A. N. (2012). Teoria das representações sociais e ALCESTE: contribuições teórico-metodológicas na pesquisa qualitativa. Saúde e Transformação Social, 3(4), 4-10.

Camargo, B. V., \& Justo, A. M. (2013). IRAMUTEQ: um software gratuito para análise de dados textuais. Temas em Psicologia, 21(2), 513-518.

Cavalcante, P. (2013). A competição eleitoral gera governos mais eficientes? Um estudo comparado das prefeituras no Brasil. Revista de Administração Pública, 47(6), 1569-1592.

Cingolani, L. (2013). The state of State capacity: a review of concepts, evidence and measures (UNU-MERIT Working Paper Series, n. 31). Maastricht, The Netherlands: United Nations University, Maastricht Economic and Social Research and Training Centre on Innovation and Technology.

Constituição da República Federativa do Brasil de 1988. (1988). Brasília, DF: Presidência da República. Recuperado de http://www. planalto.gov.br/ccivil_03/constituicao/constituicao.htm

Coordenação de Aperfeiçoamento de Pessoal de Nível Superior. (2018). Portal de periódicos CAPES. Recuperado de www.periodicos. capes.gov.br

Costa, J. M. B. S., Felisberto, E., Bezerra, L. C. A., Cesse, E. A. P. \& Samico, I. C. (2013). Monitoramento do desempenho da gestão da vigilância em saúde: instrumento e estratégias de uso. Ciência \& Saúde Coletiva, 18(5), 1201-1216.

Cruz, M. C. M. T., Montoro, F. A. F., Bio, S. R., Viana, M. T., Craveiro, S. S., \& Castro, T. P. (2011). Gestão pública no Estado de São Paulo: elementos para um olhar analítico. In J. F. A. Veloso, L. M. Monasterio, R. S. Vieira, \& R. B. Miranda (Orgs.), Gestão municipal no Brasil: um retrato das prefeituras (pp. 87-140). Brasília, DF: Instituto de Pesquisa Econômica Aplicada.

DeRouen, K., Jr., Ferguson, M. F., Norton, S., Park, Y. H., Lea, J., \& Streat-Bartlett, A. (2010). Civil war peace agreement implementation and State capacity. Journal of Peace Research, 47(3), 333-346.

Evans, P. (1995). Embedded autonomy: States and industrial transformation. Princeton, NJ: Princeton University Press.
Evans, P. B., Rueschmeyer, D., \& Skocpol, T. (2002). On the road toward a more understanding of the state. In P. B. Evans, D. Rueschmeyer \& T. Skocpol (Eds.), Bringing the State Back In (pp. 347-366). Cambridge, UK: Cambridge University Press.

Evers, J. C. (2011). From the past into the future. How technological developments change our ways of data collection, transcription and analysis. Forum: Qualitative Social Research, 12(1), 1-31.

Fernandes, F. S. (2016). Capacidade institucional: uma revisão de conceitos e programas federais de governo para o fortalecimento da administração pública. Cadernos EBAPE.BR, 14(3), 695-704.

Gibbs, G. (2009). Análise de dados qualitativos. Porto Alegre, RS: Bookman.

Glosbe. (2018). Dicionário multilíngue. Recuperado de https://pt.glosbe.com/

Gomes, S. (2010). The multi-faceted debate on decentralization and collective welfare. Brazilian Political Science Review, 4(2), 103-128.

Hanson, J. K., \& Sigman, R. (2013). Leviathans Latent Dimensions: Measuring State Capacity for Comparative Political Research. In Proceedings of the World Bank Political Economy Brown Bag Lunch Series, Washington, DC.

Hartley, K., \& Zhang, J. (2016). Measuring Policy Capacity Through Governance Indices. In X. Wu, M. Howlett, \& M. Ramesh (Eds.), Policy Capacity and Governance: Studies in the Political Economy of Public Policy (pp. 67-97). London, UK: Palgrave Macmillan.

Henderson, S., \& Segal, E. H. (2013). Visualizing qualitative data in evaluation research. New Directions for Evaluation, 139, 53-71.

Howlett, M. (2015). ScienceDirect Policy analytical capacity: the supply and demand for policy analysis in government. Policy and Society, 34(3-4), 173-182.

Huerta, R. A. (2008). Una ruta metodológica para evaluar la capacidad institucional. Política y Cultura, 30, 119-134.

Lessik, A., \& Michener, V. (2000). Measuring institutional capacity (Recent Practices in Monitoring and Evaluation Tips, n. 15). Washington, DC: International Development Cooperation Agency/United States Agency for International Development.

Levy, Y., \& Ellis, T. J. (2006). A system approach to conduct an effective literature review in support of information systems research. Informing Science Journal, 9, 181-212.

Lindvall, J., \& Teorell, J. (2016). State capacity as power: a conceptual framework. Lund: Department of Political Science, 16(1), 1-32.

Litvack, J., Ahmad, J., \& Bird, R. (1998). Rethinking decentralization in developing countries. Washington, DC: World Bank.

Lopes, S. A. (1997). A teia invisível. Informação e contra-informação nas redes de ONGs e movimentos sociais (Tese de Doutorado). Universidade Federal do Rio de Janeiro, Rio de Janeiro, RJ.

Lubambo, C. W. (2002). Conselhos gestores e desempenho da gestão nos municípios: potencialidades e limites (Textos para Discussão, n. 149). Recife, PE: Fundação Joaquim Nabuco. 
Lubambo, C. W., \& Coutinho, H. G. (2004). Conselhos gestores e o processo de descentralização. São Paulo em Perspectiva, 18(4), 62-72.

MAXQDA. (2018). Qualitative data analysis software. Recuperado de http://www.maxqda.com/

Mizrahi, Y. (2004). Capacity enhancement indicator: review of the literature. Washington, DC: World Bank Institute.

Molina, J. L., Muños, J. M., \& Doménech, M. (2002). Redes de publicaciones científicas: un análisis de la estructura de coautorías. Revista Hispana para el Análisis de Redes Sociais, 1(3), 223-238.

Nascimento, A. R. A., \& Menandro, P. R. M. (2006). Análise lexical e análise de conteúdo: Uma proposta de utilização conjugada. Estudos e Pesquisas em Psicologia, 6(2), 72-88

Neitzk, A. C. A., Gonçalves, G. P, Oliveira, R. M., Machado, D. G., \& Gibbon, A. R. O. (2015). Custos ambientais: um estudo exploratório na Região Sul do Brasil. Revista de Gestão, Finanças e Contabilidade, 5(2), 71-86.

Oates, W. E. (1999). An essay on fiscal federalism. Journal of Economic Literature, 37(3), 1120-1149.

Painter, M., \& Pierre, J. (2005). Unpacking policy capacity: issues and themes. In M. Painter, \& J. Pierre (Eds.), Challenges to State policy capacity (pp. 1-18). New York, NY: Palgrave Macmillan.

Pallotti, P. L. M., \& Costa, B. L. D. (2011). Relações intergovernamentais e descentralização. Revista de Sociologia e Política, 19(39), 211-235.

Pedroso, B., \& Pilatti, L. (2009). O novo Qualis: perspectivas para a pós-graduação em engenharia de produção. Revista Gestão Industrial, 5(2), 44-60.

Peterson, J., Pearce, P. F., Ferguson, L. A., \& Langford, C. A. (2017). Understanding scoping reviews: definition, purpose, and process. Journal of the American Association of Nurse Practitioners, 29(1), 12-16.

Ramos, A., Faria, M., \& Faria, A. (2014). Systematic review: contribution to innovation in educational research. Revista Diálogo Educacional, 14(41), 17-36.

Ratinaud, P., \& Marchand, P. (2012). Application de la méthode ALCESTE aux (gros), corpus et stabilité des (mondes lexicaux): analyse du (cablegate) avec IRAMUTEQ. In Annales de 11ㅇo Journées Internationales D’Analyse Statistique des Données Textuelles, Liège, Belgic.

Romancini, R. (2010). O que é uma citação? A análise de citações na ciência. Intexto, 2(12), 20-35.

Rumrill, P. D., Fitzgerald, S. M., \& Merchant, W. R. (2010). Using scoping literature reviews as a means of understanding and interpreting existing literature. IOS Press, 35, 399-404.
Saillard, E. K. (2011). Systematic versus interpretive analysis with two CAQDAS packages: NVivo and MAXQDA. Forum: Qualitative Social Research, 12(1), 1-21.

Silva, A. L. N. (2015). Os estados no SUAS: uma análise da capacidade institucional dos governos estaduais na assistência social. Revista de Administração Pública, 49(5), 1167-1192.

Silva, E. P. S., Fonseca, E. S., Mafra, S. C. T., \& Freitas, N. C. (2016). O idoso no contexto familiar: uma abordagem a partir do banco de dados da Capes. Sociedade em Debate, 22(2), 299-318.

Silva, L., Cunha, M., Domingos, A. \& Torres, M. (2015). Instituições políticas e desenvolvimento econômico: evidências de um estudo empírico? Revista Estudos Institucionais, 1(1), 1-28.

Skocpol, T. (1985). Bringing the State back. In P. Evans, D. Rueschemeyer, \& T. Skocpol (Ed.), Strategies of analysis in current research (pp. 3-43). Cambridge, UK: Cambridge University Press.

Soares, M. (1989). Alfabetização no Brasil: o estado do conhecimento. Brasília, DF: Instituto Nacional de Estudos e Pesquisas Educacionais Anísio Teixeira/Ministério da Educação.

Souza, C. (2005). Federalismo, desenho contitucional e instituições federativas no Brasil pós-1988. Revista de Sociologia e Política, 24, 105-121.

Veloso, J. F. A., Monasterio, L. M., Vieira, R. S., \& Miranda, R. B. (2011). Uma visão inicial dos subsistemas da gestão pública municipal. In J. F. A. Veloso, L. M. Monasterio, R. S. Vieira, \& R. B. Miranda (Orgs.), Gestão municipal no Brasil: um retrato das prefeituras (pp. 11-40). Brasília, DF: Instituto de Pesquisa Econômica Aplicada.

Vidal, J. P. (2014). A Defensoria Pública do Estado do Pará: uma observação sistêmica da capacidade institucional. Revista de Administração Pública, 48(3), 667-694.

Wasserman, S., \& Faust, K. (1994). Social network analysis. Cambridge, UK: Cambridge University Press.

Wattenberg, M., \& Viégas, F. (2008). The word tree, an interactive visual concordance. IEEE Transaction on Visualization and Computer Graphics, 14(6), 1221-1228.

Wu, X., Ramesh, M., \& Howlett, M. (2015). Policy capacity: a conceptual framework for understanding policy competences and capabilities. Policy and Society, 34(3-4),165-171.

Zampier, M. B. (2007). Movimentos sociais, apropriação das tecnologias da informação e comunicação e a centralidade na rede da Coordinadora Latinoamericana de Organizaciones del Campo (Dissertação de Mestrado). Universidade Federal de Viçosa, Viçosa, MG.

Douglas Gomes Martins

ORCID: https://orcid.org/0000-0002-9883-6716

Mestre e professor em Administração do IFPA/Campus Paragominas. E-mail: dougmartins08@gmail.com 


\begin{tabular}{|c|c|c|c|c|c|c|}
\hline 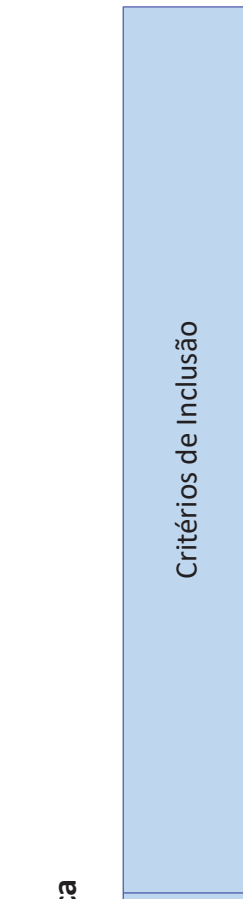 & 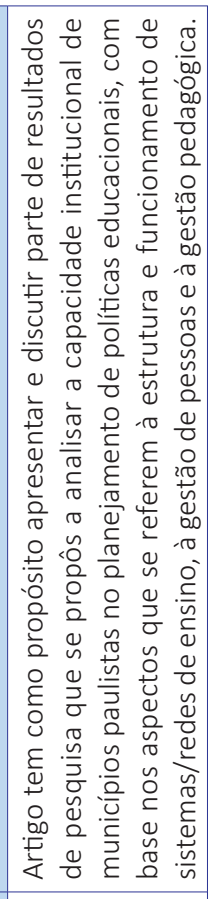 & 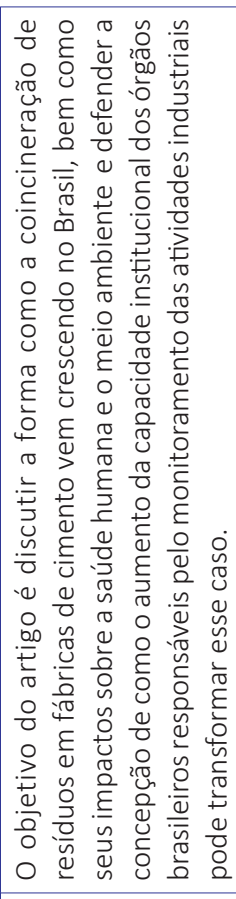 & 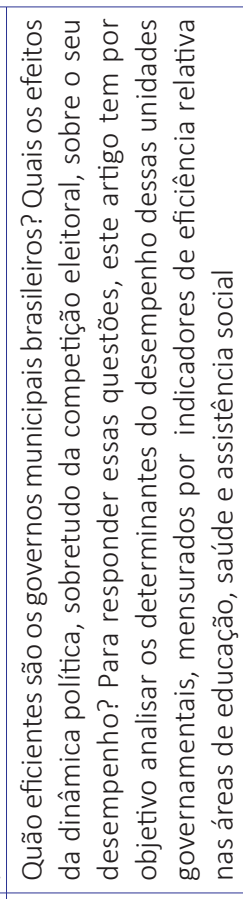 & 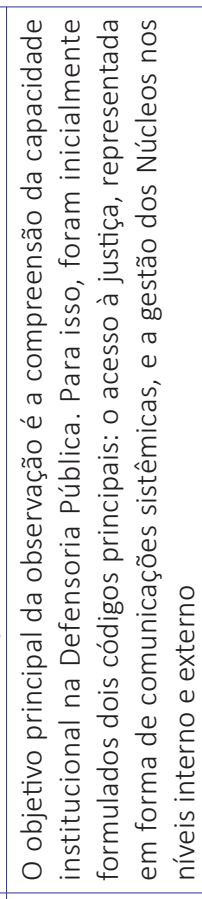 & 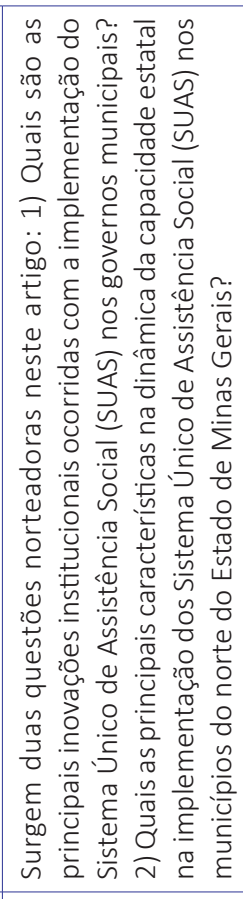 & 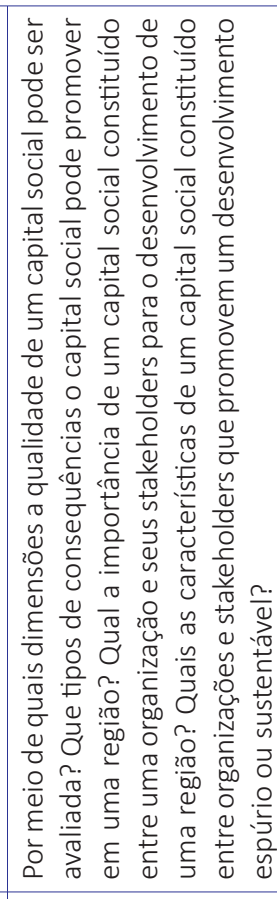 \\
\hline 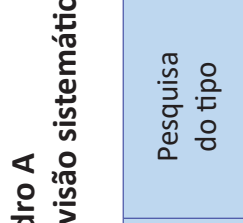 & 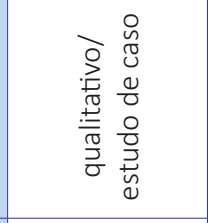 & 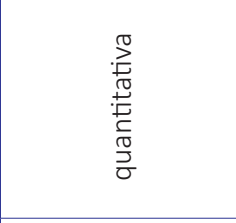 & 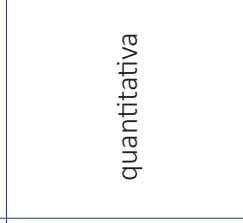 & 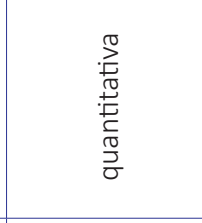 & 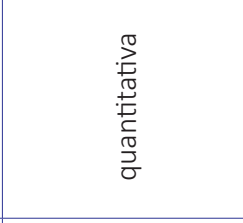 & 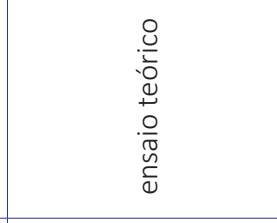 \\
\hline 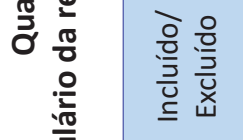 & $\begin{array}{l}\frac{0}{0} \\
\frac{0}{3} \\
\frac{9}{5}\end{array}$ & $\begin{array}{l}\frac{0}{0} \\
\frac{0}{3} \\
. \underline{\underline{C}}\end{array}$ & $\begin{array}{l}\frac{0}{0} \\
\frac{0}{3} \\
\underline{\underline{C}}\end{array}$ & $\begin{array}{l}\frac{O}{O} \\
\frac{O}{3} \\
. \underline{I}\end{array}$ & $\begin{array}{l}\frac{0}{0} \\
\frac{0}{3} \\
. \underline{E}\end{array}$ & 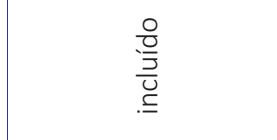 \\
\hline 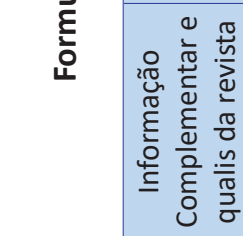 & 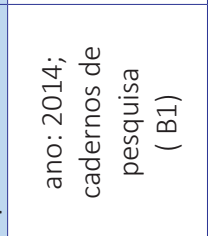 & 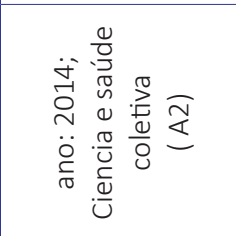 & 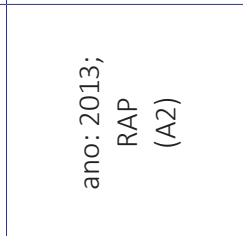 & 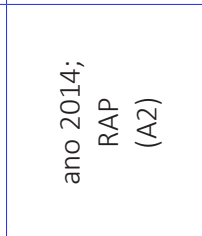 & 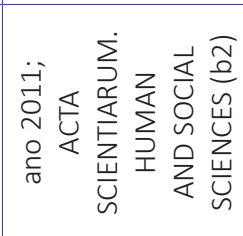 & 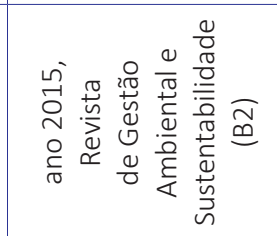 \\
\hline 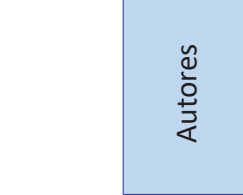 & 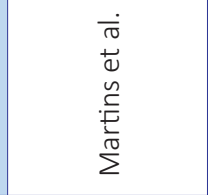 & 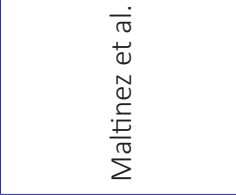 & 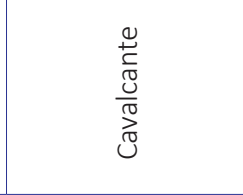 & $\begin{array}{l}\frac{\bar{\pi}}{0} \\
\frac{10}{5}\end{array}$ & 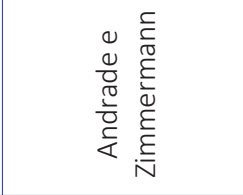 & $\begin{array}{l}\dot{\bar{O}} \\
+\frac{0}{0} \\
\frac{0}{U} \\
\sum\end{array}$ \\
\hline 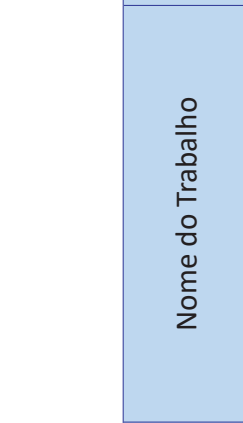 & 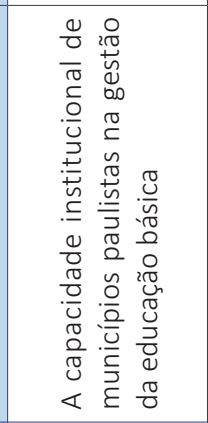 & 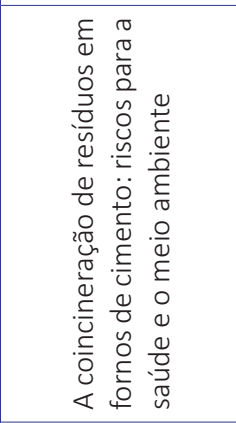 & 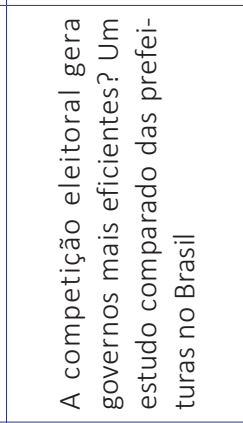 & 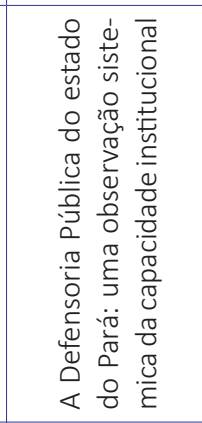 & 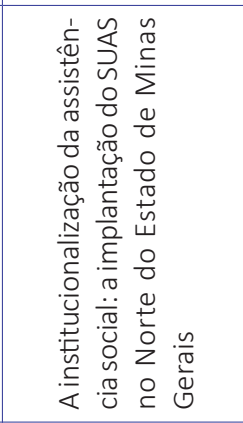 & 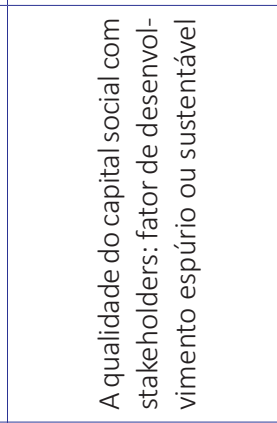 \\
\hline 으 & - & $\sim$ & $m$ & 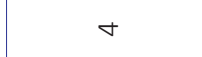 & in & 6 \\
\hline
\end{tabular}




\begin{tabular}{|c|c|c|c|c|c|c|}
\hline 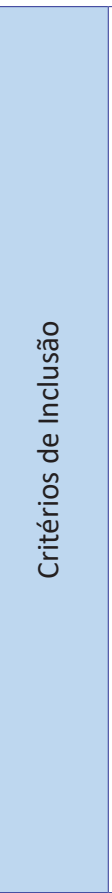 & 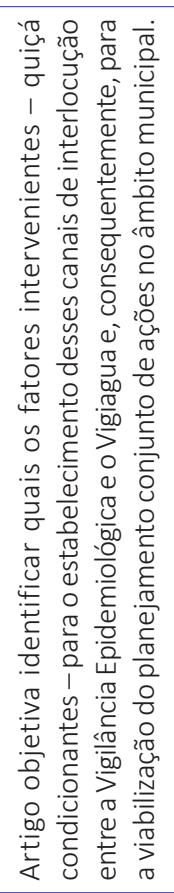 & 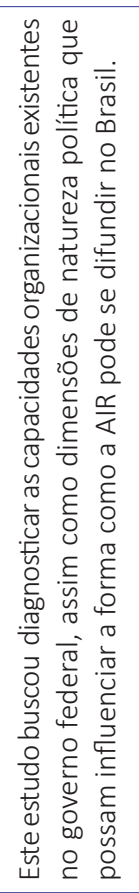 & 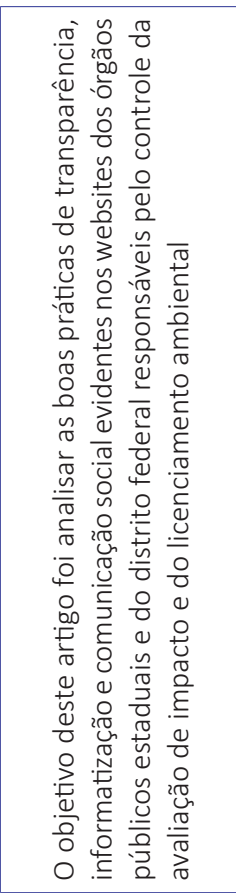 & 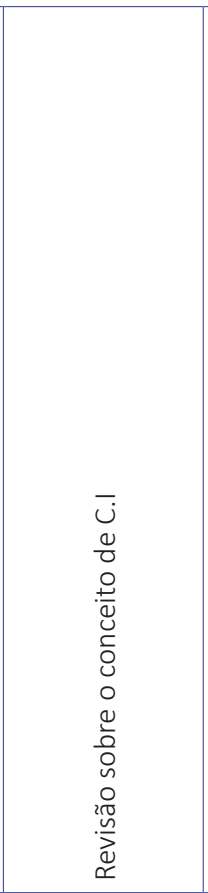 & 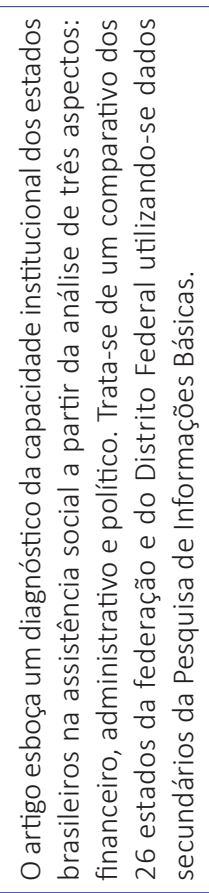 & 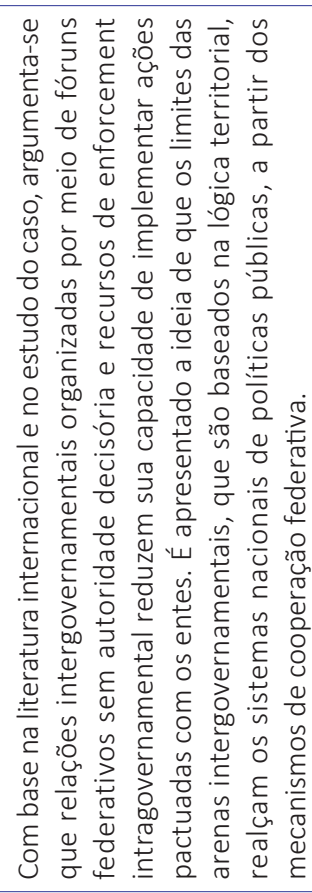 \\
\hline 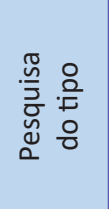 & 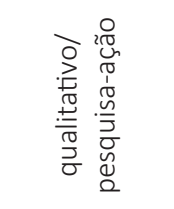 & 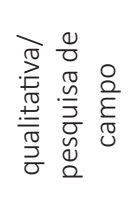 & 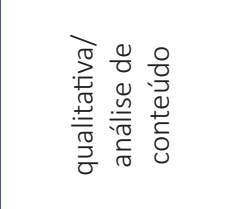 & 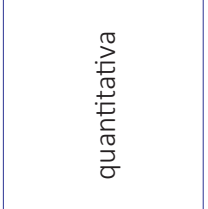 & 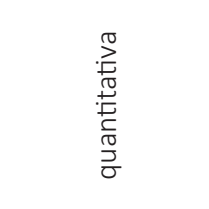 & 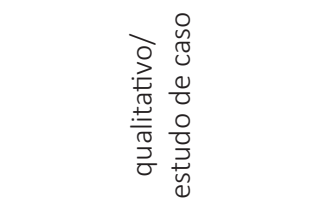 \\
\hline 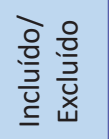 & $\begin{array}{l}\frac{0}{0} \\
\frac{0}{5} \\
. \\
.\end{array}$ & $\begin{array}{l}\frac{0}{0} \\
\frac{0}{5} \\
\underline{\underline{O}}\end{array}$ & $\begin{array}{l}\frac{0}{0} \\
\frac{0}{5} \\
. !\end{array}$ & $\begin{array}{l}\frac{0}{0} \\
\frac{0}{3} \\
. \\
.\end{array}$ & $\begin{array}{l}\frac{0}{0} \\
\frac{0}{3} \\
. \subseteq\end{array}$ & $\begin{array}{l}\frac{0}{0} \\
\frac{0}{3} \\
. \subseteq\end{array}$ \\
\hline 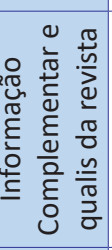 & 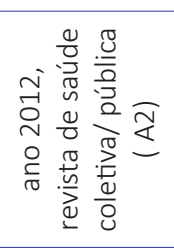 & 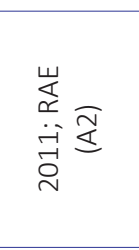 & 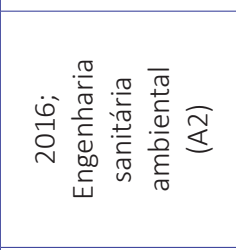 & 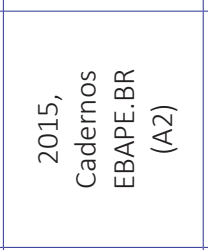 & 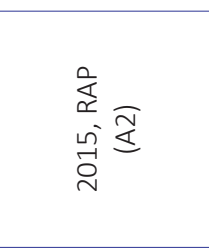 & 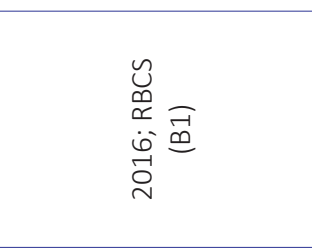 \\
\hline 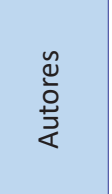 & 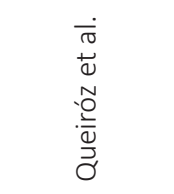 & $\begin{array}{l}\bar{\otimes} \\
\alpha\end{array}$ & 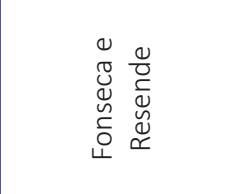 & 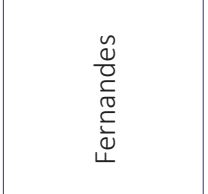 & $\frac{\pi}{i n}$ & 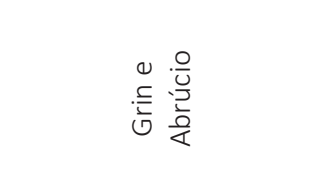 \\
\hline 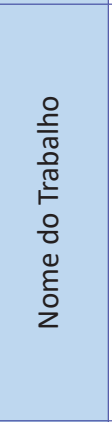 & 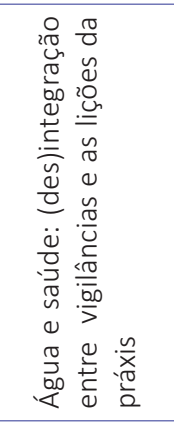 & 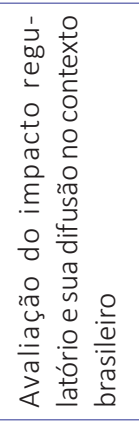 & 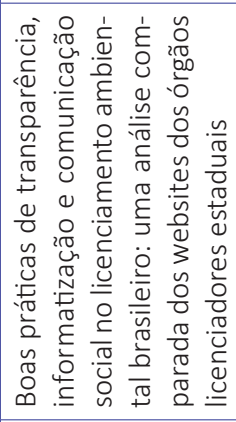 & 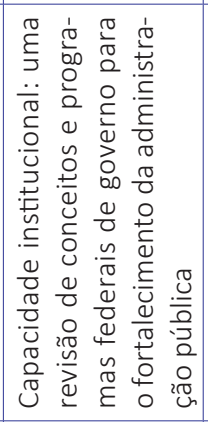 & 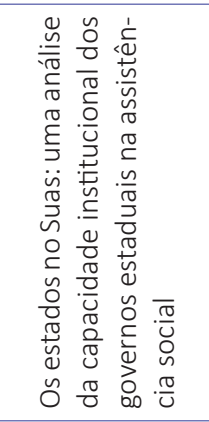 & 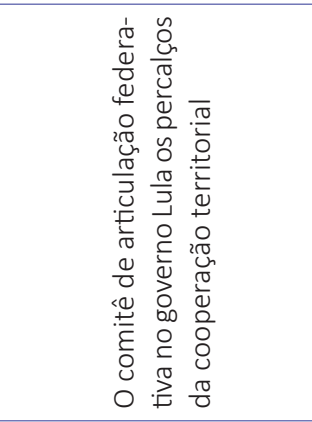 \\
\hline 은 & $\wedge$ & $\infty$ & $\sigma$ & 아 & $\stackrel{\rightarrow}{\neg}$ & ㄱ \\
\hline
\end{tabular}




\begin{tabular}{|c|c|c|c|c|}
\hline 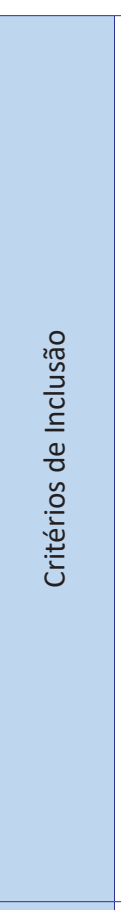 & 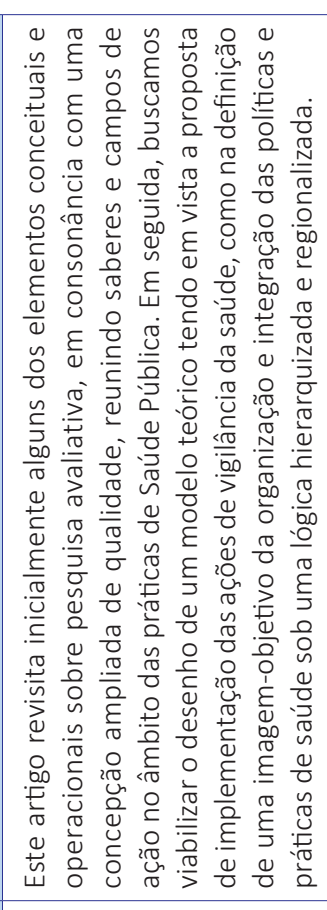 & 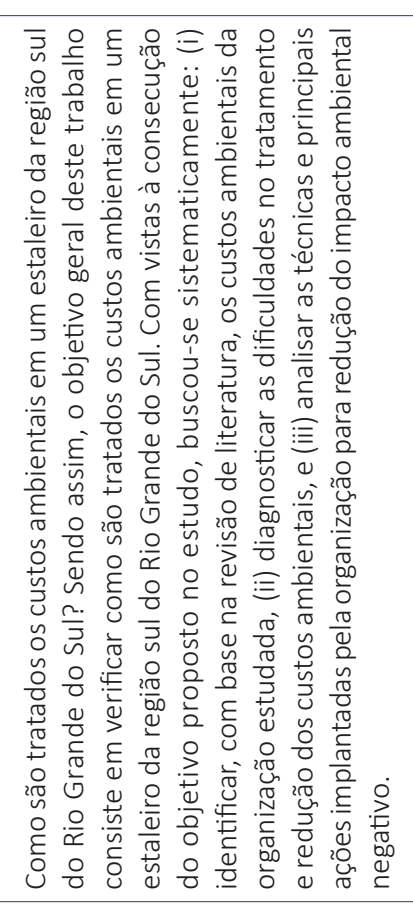 & 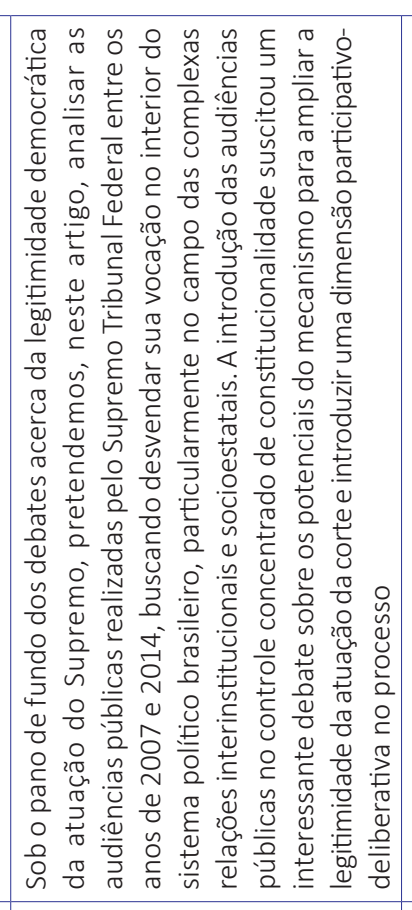 & 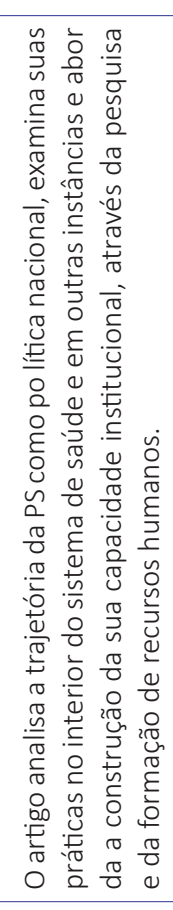 \\
\hline 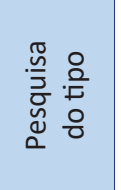 & 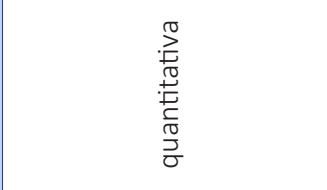 & 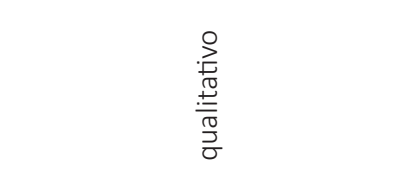 & 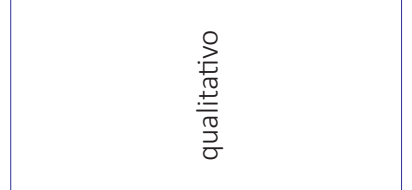 & 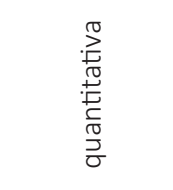 \\
\hline 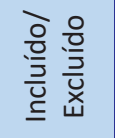 & $\begin{array}{l}\stackrel{\circ}{\frac{O}{3}} \\
\frac{\text { Un }}{\subseteq}\end{array}$ & $\stackrel{\circ}{\frac{0}{\overline{3}}}$ & 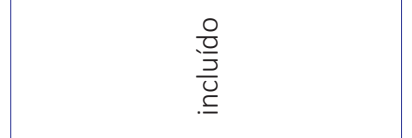 & 융 \\
\hline 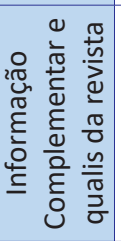 & 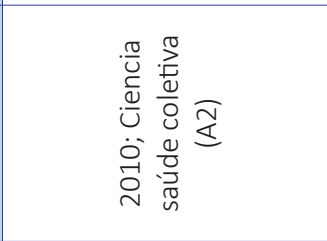 & 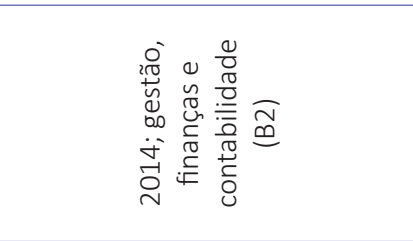 & 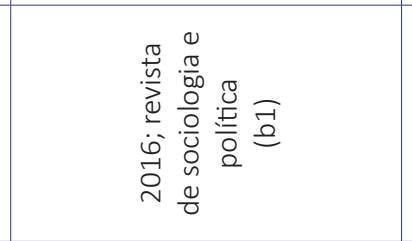 & 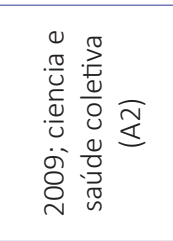 \\
\hline 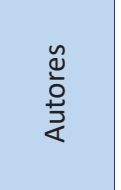 & 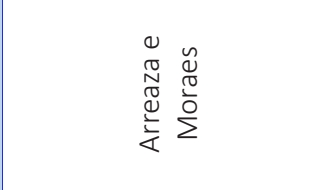 & 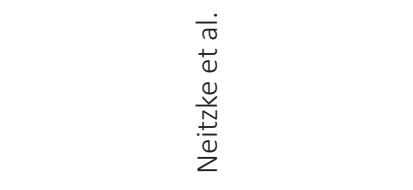 & 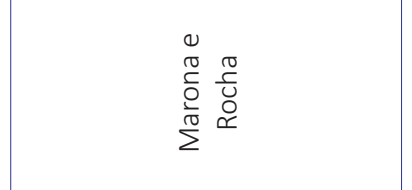 & 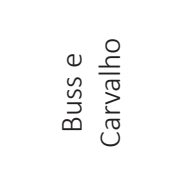 \\
\hline 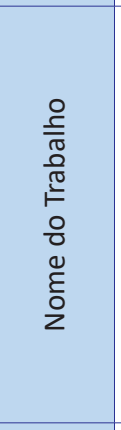 & 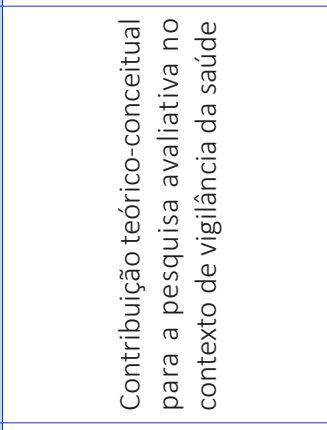 & 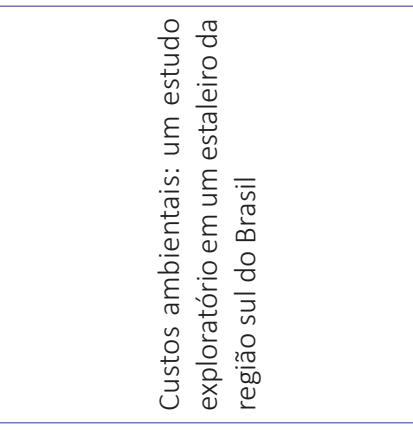 & 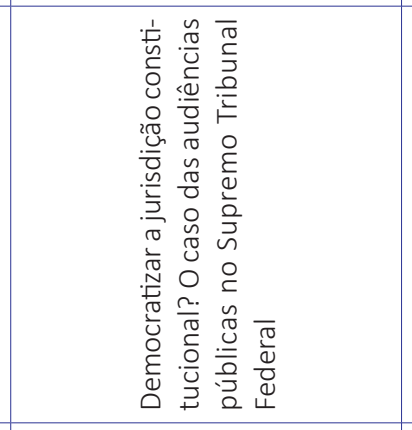 & 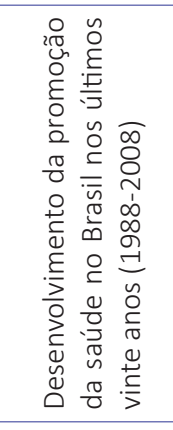 \\
\hline$\varrho$ & $m$ & $\exists$ & 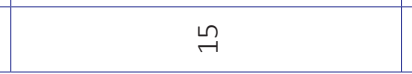 & $\stackrel{\sim}{-1}$ \\
\hline
\end{tabular}




\begin{tabular}{|c|c|c|c|c|c|}
\hline 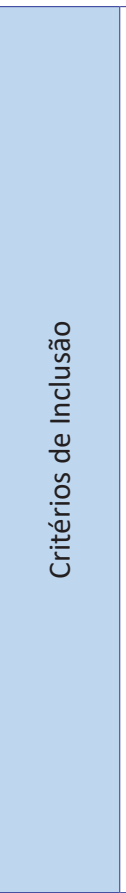 & 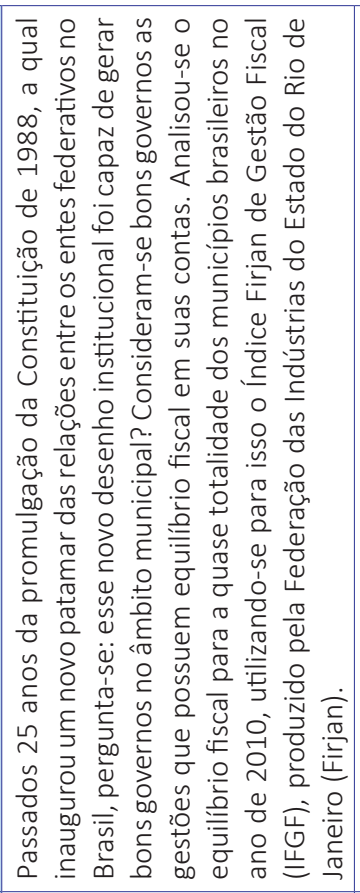 & 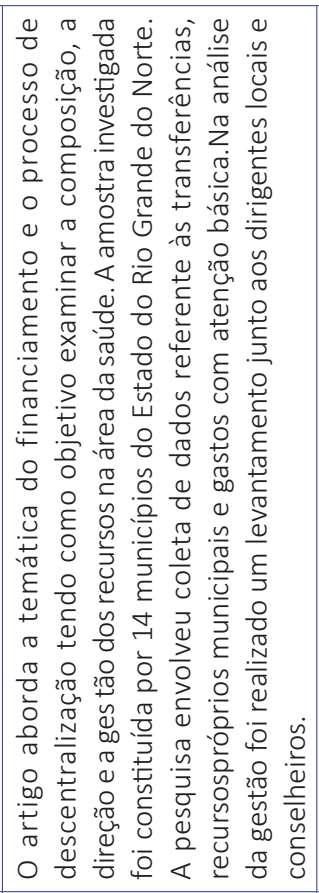 & 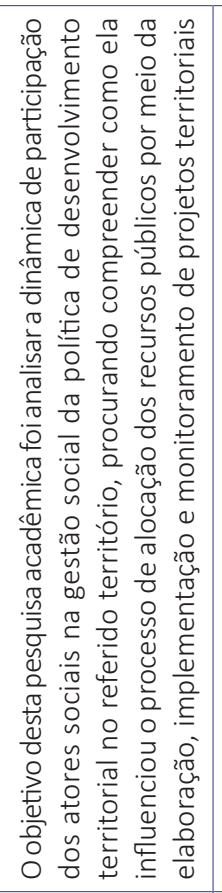 & 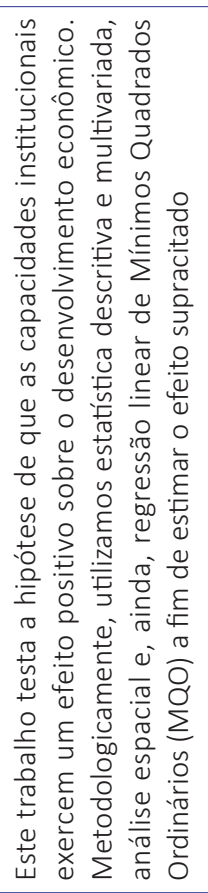 & 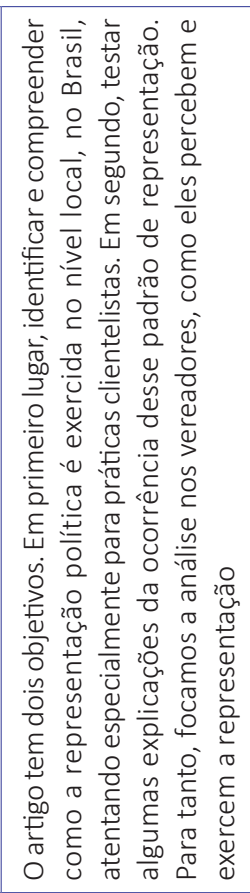 \\
\hline 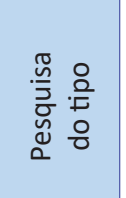 & 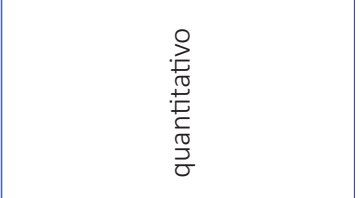 & 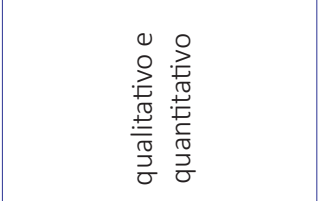 & 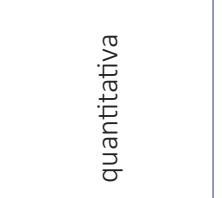 & 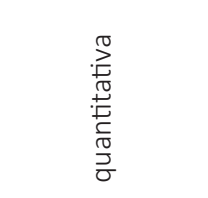 & 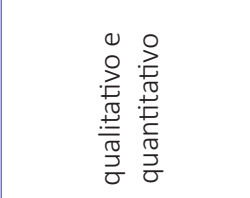 \\
\hline 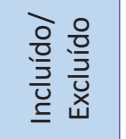 & $\begin{array}{l}\frac{0}{0} \\
\frac{0}{3} \\
. \underline{\Xi} \\
.\end{array}$ & $\begin{array}{l}\frac{0}{0} \\
\frac{0}{3} \\
. \pm\end{array}$ & $\begin{array}{l}\frac{0}{0} \\
\frac{0}{3} \\
. \subseteq\end{array}$ & $\begin{array}{l}\frac{0}{0} \\
\frac{0}{y} \\
. \subseteq \\
.5\end{array}$ & $\begin{array}{l}\frac{0}{0} \\
\frac{0}{3} \\
. \subseteq\end{array}$ \\
\hline 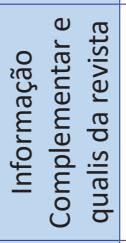 & 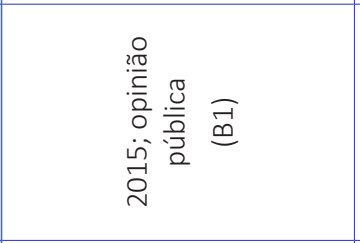 & 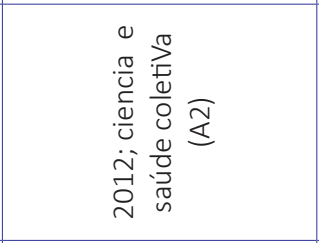 & 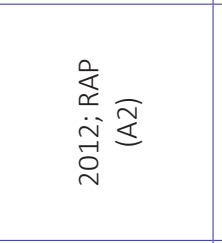 & 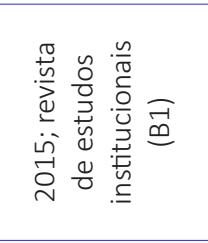 & 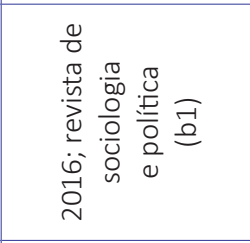 \\
\hline 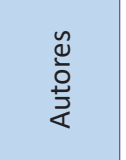 & 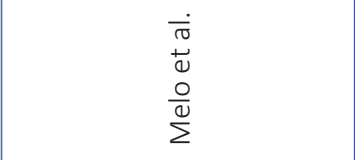 & 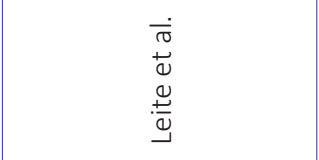 & $\begin{array}{l}\frac{\dot{0}}{\pi} \\
+\frac{0}{0} \\
\frac{5}{\pi} \\
\frac{\pi}{4}\end{array}$ & 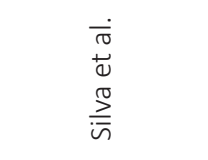 & 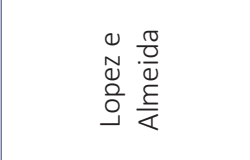 \\
\hline 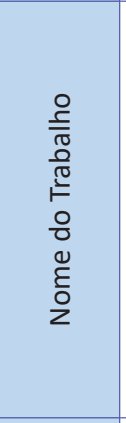 & 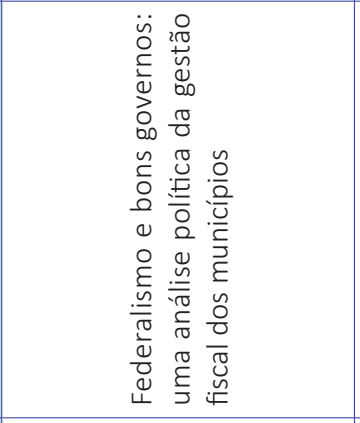 & 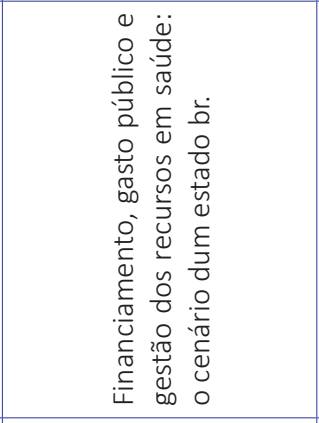 & 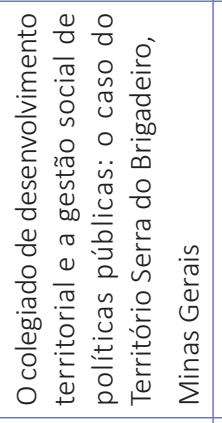 & 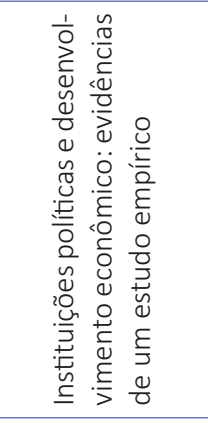 & 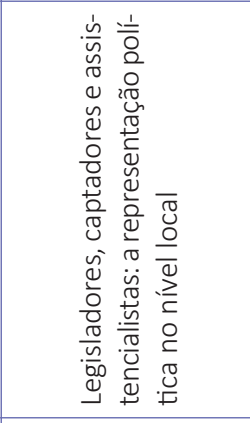 \\
\hline$\subseteq$ & ને & $\stackrel{\infty}{\sim}$ & $\underset{ન}{\sigma}$ & $\stackrel{\sim}{ }$ & $\vec{\sim}$ \\
\hline
\end{tabular}




\begin{tabular}{|c|c|c|c|c|c|c|}
\hline 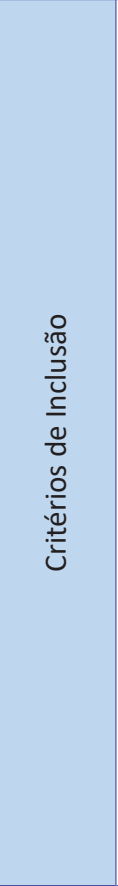 & 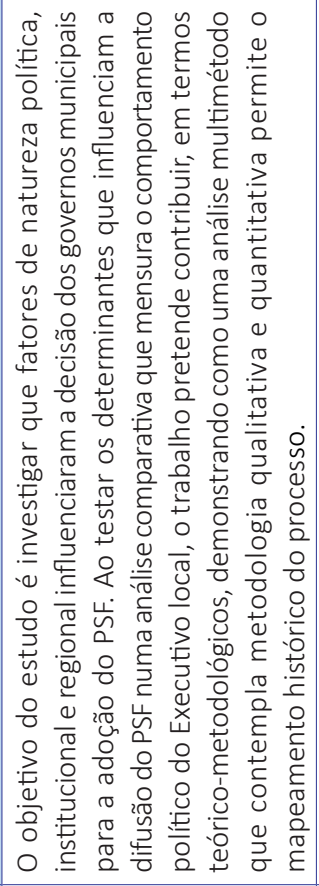 & 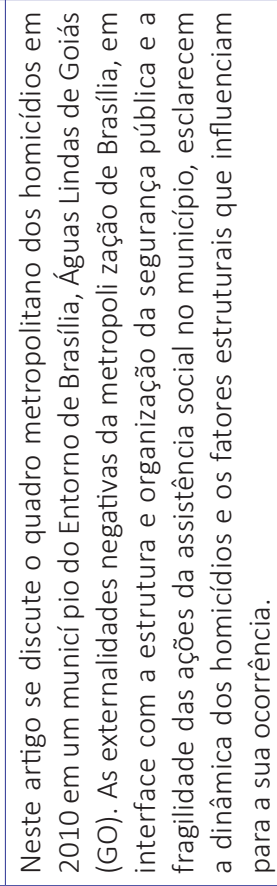 & 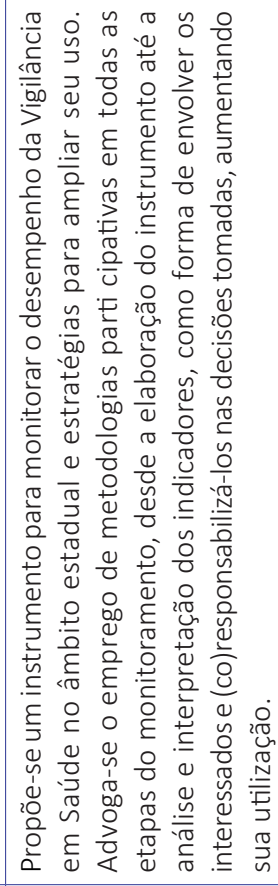 & 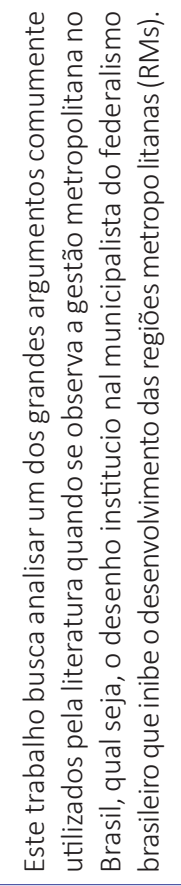 & 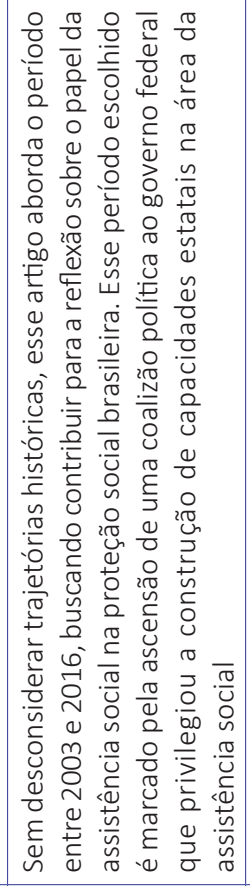 & 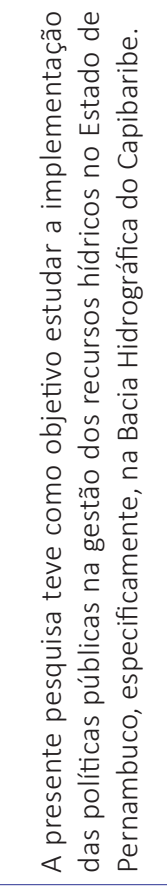 \\
\hline 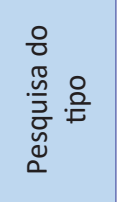 & 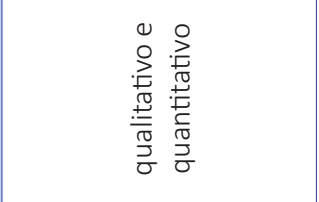 & 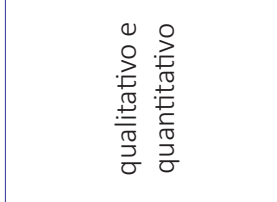 & 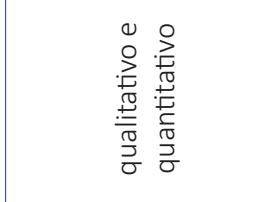 & 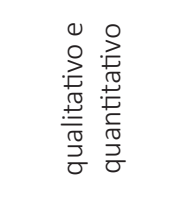 & 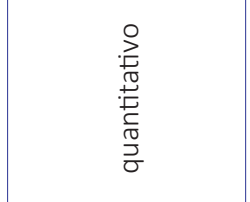 & 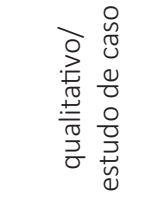 \\
\hline $\begin{array}{l}\text { 응 을 } \\
\frac{0}{3} \\
\frac{3}{y} \\
\text { 뜨 }\end{array}$ & $\begin{array}{l}\frac{0}{0} \\
\frac{0}{3} \\
. \frac{0}{I}\end{array}$ & $\begin{array}{l}\frac{0}{0} \\
\frac{0}{3} \\
\frac{0}{E} \\
.\end{array}$ & $\begin{array}{l}\frac{0}{0} \\
\frac{0}{3} \\
. \frac{1}{I}\end{array}$ & $\begin{array}{l}\frac{0}{0} \\
\frac{0}{3} \\
\frac{0}{E} \\
.\end{array}$ & $\begin{array}{l}\frac{0}{0} \\
\frac{0}{3} \\
. \subseteq\end{array}$ & $\begin{array}{l}\frac{0}{.0} \\
\frac{.0}{U} \\
. \frac{E}{I}\end{array}$ \\
\hline 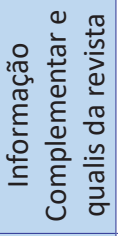 & 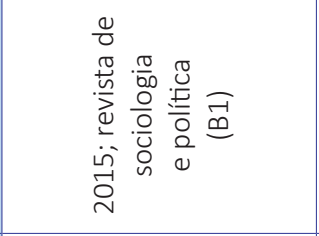 & 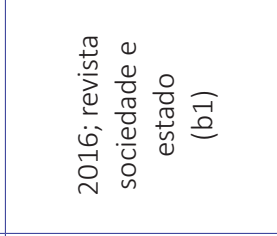 & 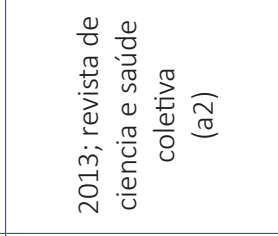 & 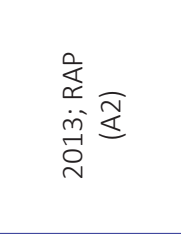 & 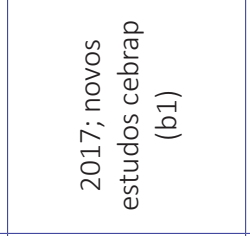 & 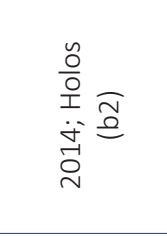 \\
\hline $\begin{array}{l}\frac{y}{0} \\
\frac{0}{0} \\
\stackrel{+}{*}\end{array}$ & $\begin{array}{l}\dot{\bar{\sigma}} \\
\stackrel{0}{0} \\
0 \\
\stackrel{0}{\overline{0}} \\
0 \\
0\end{array}$ & 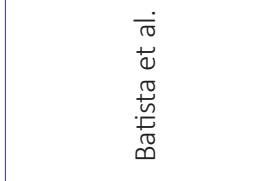 & 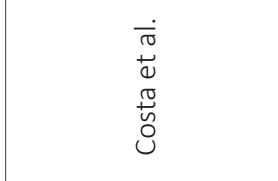 & 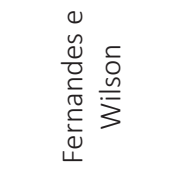 & 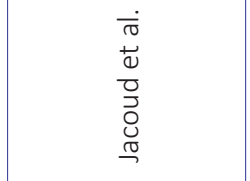 & $\begin{array}{l}\stackrel{\pi}{2} \\
i \bar{n} \\
0 \\
\frac{\pi}{2} \\
i \overline{i n}\end{array}$ \\
\hline 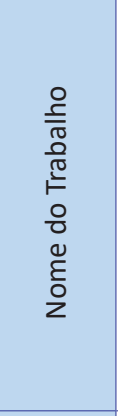 & 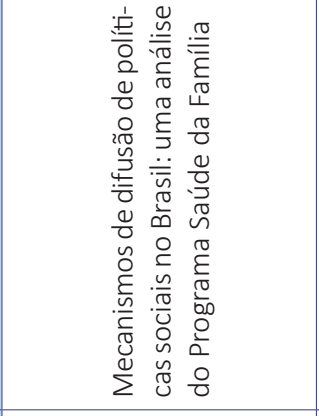 & 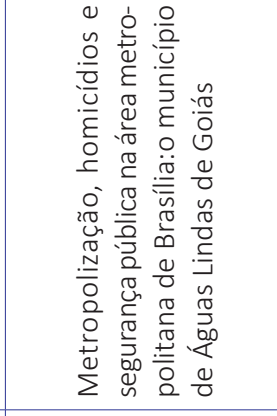 & 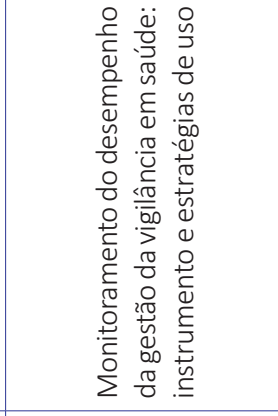 & 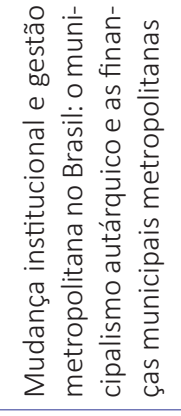 & 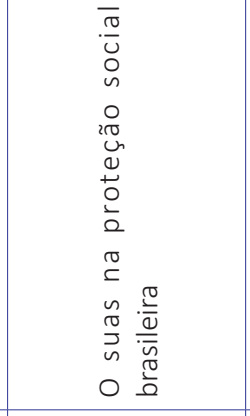 & 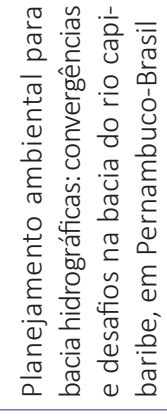 \\
\hline ㅇ & $\approx$ & $\stackrel{m}{\sim}$ & $\stackrel{\nabla}{\sim}$ & $\stackrel{\sim}{\sim}$ & $\stackrel{\bullet}{\sim}$ & $\grave{\sim}$ \\
\hline
\end{tabular}


옹

\begin{tabular}{|c|c|c|c|c|}
\hline 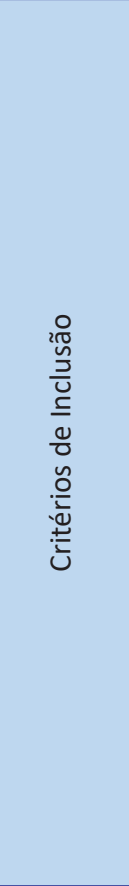 & 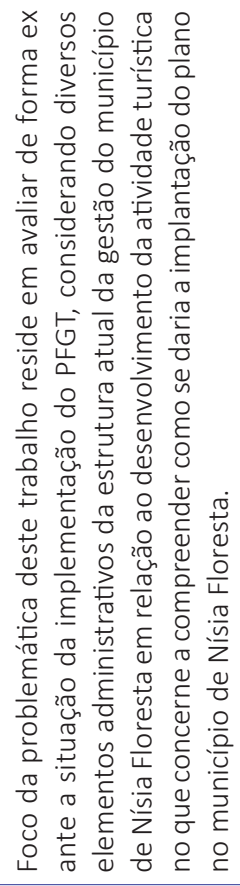 & 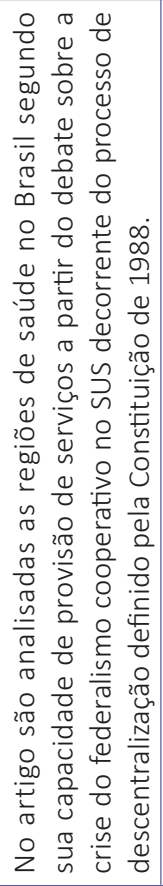 & 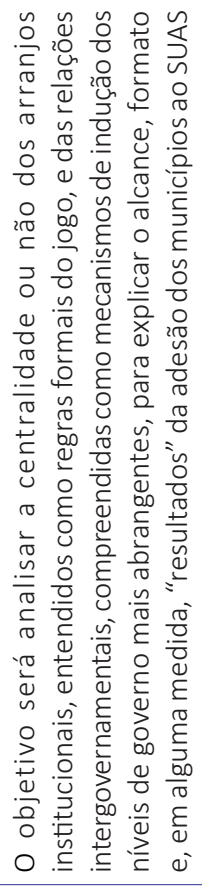 & 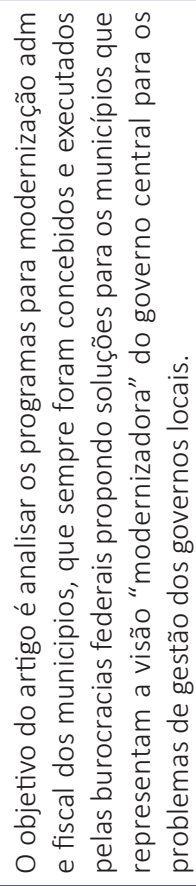 \\
\hline 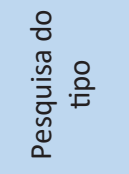 & 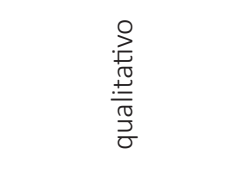 & 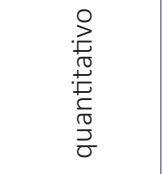 & 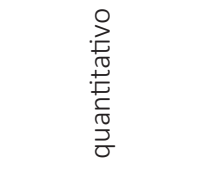 & $\begin{array}{l}\stackrel{0}{D} \\
\stackrel{D}{\pi} \\
\stackrel{ \pm}{ \pm} \\
\frac{\pi}{\sigma} \\
\sigma\end{array}$ \\
\hline 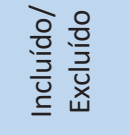 & $\begin{array}{l}\frac{O}{0} \\
\frac{.0}{U} \\
. \subseteq\end{array}$ & $\frac{\frac{0}{0}}{\frac{O}{3}}$ & $\begin{array}{l}\frac{0}{0} \\
\frac{0}{3} \\
. \frac{0}{5}\end{array}$ & $\begin{array}{l}\frac{}{0} \\
\frac{0}{3} \\
. \frac{0}{I}\end{array}$ \\
\hline 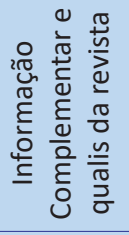 & 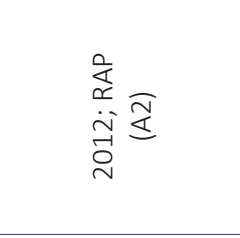 & 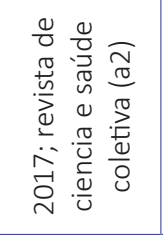 & 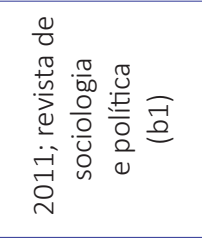 & 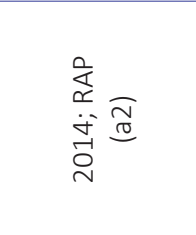 \\
\hline $\begin{array}{l}0 \\
\frac{1}{0} \\
\frac{3}{2}\end{array}$ & 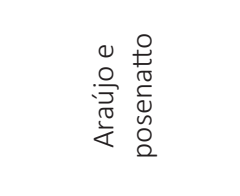 & $\begin{array}{l}\dot{\bar{\sigma}} \\
+\frac{0}{0} \\
\stackrel{ᄋ}{\bar{d}} \\
\frac{0}{\bar{\alpha}}\end{array}$ & 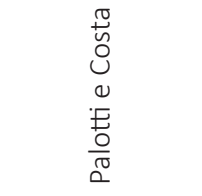 & 竞 \\
\hline 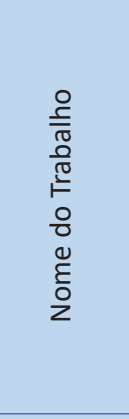 & 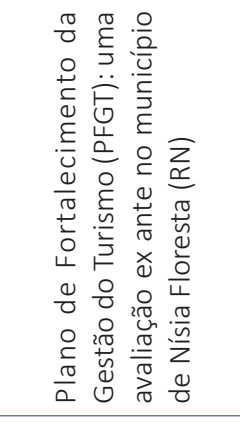 & 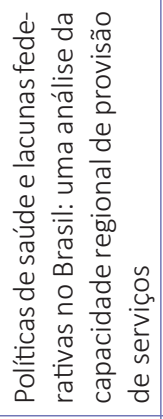 & 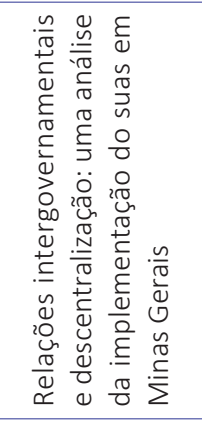 & 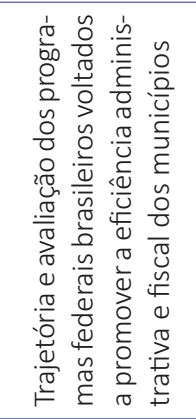 \\
\hline 으 & $\underset{\sim}{\sim}$ & సి & 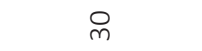 & $\vec{m}$ \\
\hline
\end{tabular}

